\title{
Enduring medial perforant path short-term synaptic depression at high pressure
}

\author{
Adolfo E. Talpalar ${ }^{1,2 * t}$, Michele Giugliano ${ }^{3,4 t}$ and Yoram Grossman ${ }^{1}$ \\ Department of Physiology and Neurobiology, Faculty of Health Sciences, and Zlotowski Center for Neuroscience, Ben-Gurion University of the Negev, Beer-Sheva, \\ Israel \\ 2 Department of Neuroscience, Karolinska Institute, Stockholm, Sweden \\ ${ }^{3}$ Department of Biomedical Sciences, University of Antwerp, Wilrijk, Belgium \\ ${ }^{4}$ Laboratory of Neural Microcircuitry, Brain Mind Institute, Ecole Polytechnique Fédérale de Lausanne, Lausanne, Switzerland
}

\section{Edited by:}

Daniel Johnston, University of Texas, USA

\section{Reviewed by:}

Daniel Johnston, University of Texas, USA

Ege Kavalali, University of Texas, USA

\section{*Correspondence:}

Adolfo E. Talpalar, Department of Neuroscience, Karolinska Institutet,

Retzius väg 8, 17177 Stockholm,

Sweden.

e-mail: adolfo.talpalar@ki.se

${ }^{\dagger}$ Adolfo E. Talpalar and Michele

Giugliano have contributed equally to this study.
The high pressure neurological syndrome develops during deep-diving (>1.1 $\mathrm{MPa}$ ) involving impairment of cognitive functions, alteration of synaptic transmission and increased excitability in cortico-hippocampal areas. The medial perforant path (MPP), connecting entorhinal cortex with the hippocampal formation, displays synaptic frequency-dependent-depression (FDD) under normal conditions. Synaptic FDD is essential for specific functions of various neuronal networks. We used rat cortico-hippocampal slices and computer simulations for studying the effects of pressure and its interaction with extracellular $\mathrm{Ca}^{2+}\left(\left[\mathrm{Ca}^{2+}\right]_{0}\right)$ on FDD at the MPP synapses. At atmospheric pressure, high $\left[\mathrm{Ca}^{2+}\right]_{0}(4-6 \mathrm{mM})$ saturated single MPP field EPSP (fEPSP) and increased FDD in response to short trains at $50 \mathrm{~Hz}$. High pressure (HP; $10.1 \mathrm{MPa}$ ) depressed single fEPSPs by $50 \%$. Increasing $\left[\mathrm{Ca}^{2+}\right]_{0}$ to $4 \mathrm{mM}$ at HP saturated synaptic response at a subnormal level (only $20 \%$ recovery of single fEPSPs), but generated a FDD similar to atmospheric pressure. Mathematical model analysis of the fractions of synaptic resources used by each fEPSP during trains (normalized to their maximum) and the total fraction utilized within a train indicate that HP depresses synaptic activity also by reducing synaptic resources. This data suggest that MPP synapses may be modulated, in addition to depression of single events, by reduction of synaptic resources and then may have the ability to conserve their dynamic properties under different conditions.

Keywords: rat, hyperbaric helium pressure, dentate gyrus, granule cells, hippocampus, synaptic dynamics, entorhinal cortex, HPNS

\section{INTRODUCTION}

The high pressure neurological syndrome (HPNS), experienced by deep-divers and animals at pressures above $1.1 \mathrm{MPa}$ (reviewed Bennett and Rostain, 2003; Talpalar, 2007), displays signs of cortico-hippocampal involvement, including impairment of episodic and spatial memory (Logue et al., 1986; Vaernes et al., 1989), and cognitive malfunction (Vaernes et al., 1985, 1988; Abraini et al., 1993; Abraini, 1997). Synaptic changes, including depression of $\mathrm{Ca}^{2+}$-entry into presynaptic terminals (reviewed Daniels and Grossman, 2003; Talpalar, 2007) and disruption of synaptic depression at short intervals (Talpalar and Grossman, 2003), distorts the low-pass filter properties of the dentate gyrus (DG) resulting in hyperexcitability (Talpalar and Grossman, 2004). The medial perforant path (MPP), originating at the entorhinal cortex and synapsing on granule cells of the DG, exhibits marked frequency-dependent-depression (FDD; Beck et al., 2000; Kilbride et al., 2001; Talpalar and Grossman, 2003). Neuronal networks use FDD (Liley and North, 1953; Elmqvist and Quastel, 1965; Zucker and Regehr, 2002) for low-pass filtering (Fortune and Rose, 2001; Fuhrmann et al., 2002; Stevens, 2003a), coding based on firing rate and spike-timing (Tsodyks and Markram, 1997), sorting information (Cook et al., 2003), avoiding habituation (Best and Wilson, 2004), dynamic gain-control of synaptic signaling (Abbott et al., 1997), for direction selectivity and contrast adaptation (Chance et al., 1998), and for sound localization (Stevens, 2003b; Cook et al., 2003). Excitatory synapses in the CNS display FDD because of limited synaptic resources (SR) including a relatively small readily releasable-pool (Schikorski and Stevens, 1997, 2001; Aravanis et al., 2003) and fast desensitization of non-NMDA receptors (Tsodyks and Markram, 1997). Then, FDD occurs when fast synaptic activity exceeds the recovery rate of SR (Bailey and Chen, 1988; Wang and Kaczmarek, 1998; Stevens and Wesseling, 1999). High extracellular calcium $\left(\left[\mathrm{Ca}^{2+}\right]_{0}\right)$ increases both single EPSP responses and FDD (Dittman and Regehr, 1998) and the opposite happens at low $\left[\mathrm{Ca}^{2+}\right]_{0}$ (Talpalar and Grossman, 2003). High pressure (HP) of 10.1 MPa decreases single fEPSP by about 50\% (Fagni et al., 1987; Talpalar and Grossman, 2003; Etzion et al., 2009), but the effect on SR dynamics is still unclear. Quantal analysis of crustacean neuromuscular synapses revealed reduction of quantal content and number of available release sites and spared quantal size and release probability at HP (Golan et al., 1994, 1995). HP-induced reduction of synaptic inputs was relieved by increasing $\left[\mathrm{Ca}^{2+}\right]_{0}$, and mimicked by lowering $\left[\mathrm{Ca}^{2+}\right]_{0}$ in both, brain and crustacean preparations. HP and low $\left[\mathrm{Ca}^{2+}\right]_{0}$ increased facilitation/potentiation in crustacean neuromuscular (Grossman and Kendig, 1990; Golan and Grossman, 1992) and cerebellar parallel fiber (Etzion and Grossman, 2000) "unsaturated" synapses. But "saturated" synapses exhibited either pressure-independent paired-pulse-depression 
(PPD) at cerebellar climbing fibers (Etzion et al., 2009) or diminished MPP's PPD (Talpalar and Grossman, 2003). Curiously, while lowering $\left[\mathrm{Ca}^{2+}\right]_{\mathrm{o}}$ switched MPP's FDD into frequency-dependentpotentiation, HP preserved FDD (Talpalar and Grossman, 2003). This dichotomy led us to hypothesize that HP has special effects on the dynamics of SR. We used electrophysiology and quantitative mathematical modeling for studying the dynamics of the MPP synapse under different $\left[\mathrm{Ca}^{2+}\right]_{\mathrm{o}}$ and pressure conditions in an attempt to understand HPNS and adaptation to HP.

\section{MATERIALS AND METHODS BRAIN SLICE PREPARATION}

Sprague-Dawley rats of both sexes (150-250 g) were anesthetized with pentobarbital $(60 \mathrm{mg} / \mathrm{kg})$ and then decapitated according to regulation of the Animal Care Committee of Ben-Gurion University. The brain was extracted in less than $1 \mathrm{~min}$ and immersed in cold Ringer's solution $\left(4-6^{\circ} \mathrm{C}\right)$. As previously described (Talpalar and Grossman, 2003), brain slices (400 $\mu \mathrm{m})$ containing corticohippocampal areas were cut in a horizontal vibratome (Campden Instruments) and conserved in an incubation container at $25^{\circ} \mathrm{C}$ for later utilization. Control Ringer's solution contained (in $\mathrm{mM}$ ): $\mathrm{NaCl} 124, \mathrm{KCl} 3, \mathrm{CaCl}_{2} 2, \mathrm{MgSO}_{4} 2, \mathrm{NaH}_{2} \mathrm{PO}_{4} 1.25, \mathrm{NaHCO}_{3} 26$, and $\mathrm{D}$-Glucose 10 . This solution was continuously bubbled with $95 \% \mathrm{O}_{2}$ and $5 \% \mathrm{CO}_{2}$ for a $\mathrm{pH}$ of 7.4 .

\section{PRESSURE AND COMPRESSION}

fEPSPs experiments at HP were carried out in a pressure chamber (Canty Inc., USA). The compression/decompression procedures have been previously described (Talpalar and Grossman, 2003, 2004). Briefly, HP up to $10.1 \mathrm{MPa}$ was attained by compressing inert helium gas at rates between 0.15 and $0.2 \mathrm{MPa} / \mathrm{min}$. Electrophysiological samples were taken at control (0.1-0.4 MPa), 5.1 and $10.1 \mathrm{MPa}$. Ringer's solution was saturated at normal pressure with $95 \% \mathrm{O}_{2}-5 \% \mathrm{CO}_{2}$ and was injected into the experimental bath by a fast high pressure pump (LDC analytical minipump, USA). Trials were collected under strict conditions of temperature $\left(30^{\circ} \mathrm{C}\right)$ and at least after 15-20 min of stable recording. Complete recovery was attained during decompression from 10.1 to $5.1 \mathrm{MPa}$. Partial degree of recovery was observed in decompression from 5.1 to $0.4 \mathrm{MPa}$. Very slow decompression below $0.4 \mathrm{MPa}$ was successful in $\sim 50 \%$ of the experiments.

\section{ELECTROPHYSIOLOGICAL RECORDINGS}

HP conditions do not allow the use of whole-cell recordings because of impossibility of manipulating pressures at the electrode level for opening of a seal for whole-cell configuration. Therefore, we used in the present study extracellular fEPSPs of the MPP, whose synaptic dynamics resembled those of synaptic currents (EPSCs) recorded during whole-cell configuration (Rush et al., 2002; Talpalar, 2002). Recordings of MPP fEPSPs at the inner dendritic region of the DG, their parameters, and interpretation have been previously described in detail (Talpalar and Grossman, 2003, 2004). In summary, fEPSP's amplitude indicating inward synaptic currents, and fEPSP's slope expressing the rate of activation of the glutamatergic non-NMDA receptors, were used for assessing synaptic activity. Though fEPSP's amplitude can be used for calculation of synaptic dynamics provided they do not elicit population spikes, contamination with voltage-dependent conductances, including the NMDA receptor fraction, may impair the estimation of synaptic strength. To avoid these interferences, we exclusively used fEPSPs' slopes for the calculations. Trains of five stimuli at $50 \mathrm{~Hz}$, delivered once per minute, were used to evaluate the frequency response. Parameters of each response in these trains $\left(E_{2-5}\right)$ were usually normalized with respect to the first fEPSP $\left(E_{1}\right)$. Paired-pulsedepression (PPD) and paired-pulse-facilitation (PPF) are used for referring respectively to the relative depression or enhancement of $E_{2}$ in relation with $E_{1}$. The "generic" expression pairedpulse-modulation (PPM; positive or negative) was used for both depression and facilitation. Frequency-dependent-potentiation (FDP), frequency-dependent-depression (FDD) and the generic term frequency-dependent-modulation (FDM) (positive or negative) are used for referring to such forms of dynamic synaptic modulation.

\section{Statistical analysis of electrophysiological experiments}

The results are expressed as mean \pm SE. The $n$ is the number of slices; each comes from a different animal successfully used in each experiment. Paired Student's $t$-test was used for parameters taken under control and experimental conditions in the same slice. Other statistical tests (independent $t$-test, ANOVA, etc.) were used for comparing parameters (slope, amplitude, time constant, etc.) under various conditions. Degree of significance was indicated by the values of $p$ (the results were considered statistically different for $p<0.05)$.

\section{MATHEMATICAL MODELING}

We considered a standard phenomenological model for the interpretation of our experimental results. This model was originally introduced by Tsodyks and Markram (1997) to account for usedependent monosynaptic transmission in the cortex, and it was employed here to describe the dependence of field-responses on the frequency of repeated MPP extracellular stimulation as in Abbott et al. (1997). Because MPP synapses onto granule cells occur in their proximal dendritic area and because granule cells have no recurrent collaterals in healthy hippocampi, the validity of the model in the interpretation of population responses such as the fEPSPs has been assumed, invoking linearity and superposition of the elicited individual synaptic responses.

The model captures the frequency-dependent modulation of fEPSPs upon repetitive stimulation, by two variables: (i) the readily available synaptic resources $r$, and (ii) their fraction $u$, recruited at each stimulus for neurotransmission. It is then assumed that recruited resources $r \times u$ become instantaneously inactive, so that only the remaining amount $r \times(1-u)$ is available for further neurotransmission. In the lack of synaptic activation, the unavailable resources slowly recover so that the value $r$ increases back to its resting level $R$, exponentially with a time constant $D . R$ represents therefore the upper limit to the amount of resources available for neurotransmission.

In order to capture possible short-term facilitation effects, $u$ is not fixed but increases by $U(1-u)$ at each synaptic activation. Similarly to $r$, when no stimulation occurs $u$ slowly decreases back to its resting level $U$, exponentially with a time constant $F$. 
Then, the model predicts that each slope $S_{1}, S_{2}, S_{3}, \ldots S_{\mathrm{N}}$ of fEPSPs, elicited by a train of $N$ stimuli occurring at times $t_{1}, t_{2}, t_{3}, \ldots t_{\mathrm{N}}$, depends only on the time since last activation and on the running values of $r$ and $u$, in the form $S_{\mathrm{i}}=A r_{\mathrm{i}} u_{\mathrm{i}}$, where $r_{\mathrm{i}+1}=R+\left[\left(1-u_{\mathrm{i}}\right) \times r_{\mathrm{i}}-R\right]$ $\times \exp \left[-\left(t_{\mathrm{i}+1}-t_{\mathrm{i}}\right) / D\right], u_{\mathrm{i}+1}=U+\left[(1-U) \times u_{\mathrm{i}}\right] \times \exp \left[-\left(t_{\mathrm{i}+1}-t_{\mathrm{i}}\right) / F\right]$ (Tsodyks and Markram, 1997), and $A$ representing an amplitudescaling factor. Such a phenomenological approach is particularly appropriate when interpreting averaged or population responses, as opposed to quantal analysis (but see Loebel et al., 2009). On a first approximation, the following correspondences can be established (Markram et al., 1998; Fuhrmann et al., 2002): $U$ relates to the probability of release, while $A$ is equivalent to the product of the quantal size, the number of release sites ("quantal content" i.e., the mean number of released quanta), the maximal number of synapses recruited by extracellular MPP stimulation, and an extracellular attenuation factor.

In addition, because of linearity of the iterative equations reported above, a change in $R$ cannot be distinguished from a change in $A$. For such a reason $R$ was set to 1 in the equation, and $A$ was interpreted as both pre- and postsynaptic effective parameter.

To some extent, the same model may also describe the desensitization of the postsynaptic receptors upon repeated activation (Destexhe et al., 1994).

\section{Best-fit values and statistics of model parameters}

Optimal fitting of the model parameters was carried out through minimization of the root mean square error $\mathrm{X}^{2}$ among measured fEPSP slopes $E_{1}, E_{2}, E_{3}, \ldots E_{\mathrm{N}}$ and the corresponding model responses $S_{1}, S_{2}, S_{3}, \ldots S_{\mathrm{N}}$. The quality of each fit was expressed as a percentage error, normalized to the maximal fEPSP in the train. In experiments with varying $\left[\mathrm{Ca}^{2+}\right]_{0}$, HP or both, simultaneous fit of two or three sets of responses were performed.
For each experiment, the Levenberg-Marquardt least-square algorithm (Press et al., 1992) was used to fit the model response to the data, adjusting $A, U, D$, and $F$ to obtain the best-fit. The $\mathrm{X}^{2}$ goodness of fit (Press et al., 1992) was used as a standard test of the quality of the model in capturing the experimental observations, with a required level of significance above $99 \%$.

\section{RESULTS}

HIGH $\left[\mathrm{Ca}^{2+}\right]_{0}$ SATURATES MPP SYNAPTIC RESPONSES AT NORMAL AND HIGH PRESSURE

We previously reported that single MPP fEPSPs were depressed by $\sim 25 \%$ and $\sim 55 \%$ at 5.1 and 10.1-MPa pressure (Talpalar and Grossman, 2003). These experimental pressures are relevant because of two reasons: (a) deep-diving cetaceans reach such ambient pressures during foraging (Talpalar and Grossman, 2005, 2006); (b) they better model HP effects in humans since rodents have higher threshold for pressure-induced seizures than primates (Brauer et al., 1979).

Synaptic release is dependent on cytosolic $\mathrm{Ca}^{2+}$ levels at the terminals. Consequently, a larger $\mathrm{Ca}^{2+}$ driving force $\left(V_{\mathrm{Ca}}\right)$ increases Ca-entry, strengthening synaptic response until reaching saturation. HP reduced MPP fEPSPs probably by depressing synaptic release (Talpalar and Grossman, 2003) but it is not clear how these changes affected the level of saturation in response to variable $V_{\mathrm{Ca}}$. We dealt with this question by comparing synaptic saturation under different conditions of atmospheric pressure and HP.

Raising $\left[\mathrm{Ca}^{2+}\right]_{0}$ from 2 to $4 \mathrm{mM}$ at control pressure $(0.1 \mathrm{MPa})$ increased fEPSPs' amplitudes and slopes by $19 \pm 5 \%$ and $27 \pm 5 \%$ respectively $(n=6$; Figures $\mathbf{1 A}, \mathbf{B})$. Synaptic release apparently reached saturation at $4 \mathrm{mM}\left[\mathrm{Ca}^{2+}\right]_{\mathrm{o}}$, since further increase of $\left[\mathrm{Ca}^{2+}\right]_{\mathrm{o}}$ to $6-8 \mathrm{mM}(n=4)$ did not maintained the elevated saturation level but rather brought it down to the control levels (Figure 1B).

\section{A}

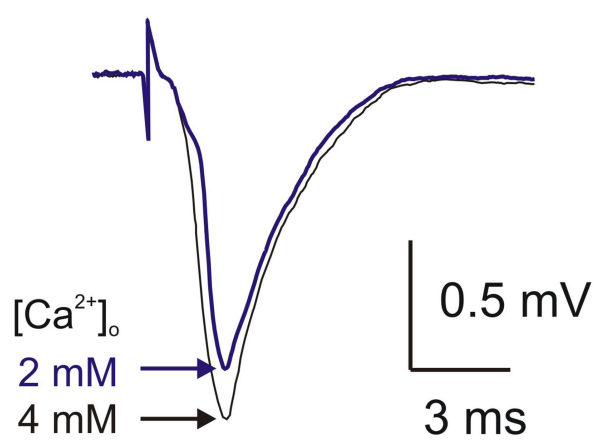

B

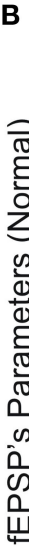

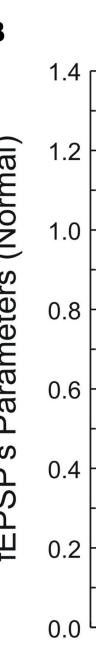

$p<0.02$
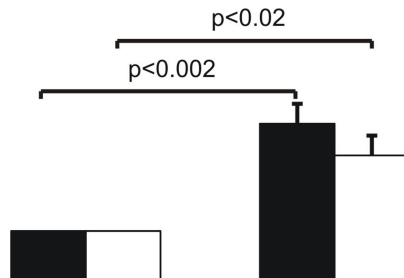

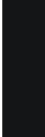

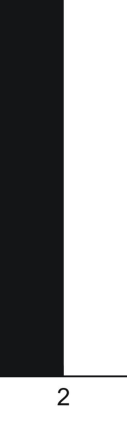

Slope

Amplitude

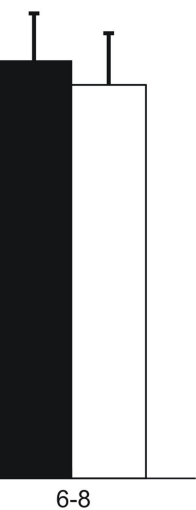

$\left[\mathrm{Ca}^{2+}\right]_{0}(\mathrm{mM})$
FIGURE 1 | Enhancement of single MPP fEPSP's by elevated $\left[\mathrm{Ca}^{2+}\right]_{0}$ under normobaric conditions. (A) fEPSPs recorded the inner dendritic area of the dentate gyrus at $\left[\mathrm{Ca}^{2+}\right]_{0} 2$ and $4 \mathrm{mM}$. (B) Statistical analysis of single fEPSPs amplitudes and slopes under $2,4,(n=6)$ and $6-8 \mathrm{mM}\left[\mathrm{Ca}^{2+}\right]_{0}(n=4)$. Note that maximal slope and amplitude were reached at $4 \mathrm{mM}\left[\mathrm{Ca}^{2+}\right]_{\mathrm{o}^{\prime}}$, apparently reaching saturation since further increase of $\left[\mathrm{Ca}^{2+}\right]$ to $6-8 \mathrm{mM}$ resulted in no change or even depression of the fEPSPs (not significantly different from fEPSPs at $2 \mathrm{mM}$ ). Scatter bars indicate mean \pm SE. 
Compression to 10.1 MPa in the present experiments reduced MPP fEPSP's slope by $48 \pm 11 \%(n=8)$. Similarly, we assessed the ability of increased $\left[\mathrm{Ca}^{2+}\right]_{\mathrm{o}}$ to relieve this decline. Raising $\left[\mathrm{Ca}^{2+}\right]_{0}$ from 2 to $4 \mathrm{mM}$ increased fEPSPs slopes by 20\% (Figures 2A,B). This enhancement of fEPSP's slope at 10.1 MPa was not statistically different (one-way ANOVA) from the enhancement produced by a similar raise in $\left[\mathrm{Ca}^{2+}\right]_{0}$ at $0.1 \mathrm{MPa}(27 \%$, as above).

It is worth noticing that the enhancement of fEPSP's slope by raising $\left[\mathrm{Ca}^{2+}\right]_{0}$ to $4 \mathrm{mM}$ at $10.1 \mathrm{MPa}$ was comparable to the effect of decompression from 10.1 to $5.1 \mathrm{MPa}$ at $2 \mathrm{mM}\left[\mathrm{Ca}^{2+}\right]_{\mathrm{o}}$, which increased single fEPSPs' slope by approximately $22 \%$ with respect to $10.1 \mathrm{MPa}$ (see below). However, this $\left[\mathrm{Ca}^{2+}\right]_{\mathrm{o}}$ increase was not sufficient to restore the responses to the control levels.

For quantitative comparison of differences in saturation level of MPP synapses under various conditions, all the responses were normalized with respect to a single "saturated" maximal fEPSP $\left(E_{1}\right)$ under conditions of $4 \mathrm{mM}\left[\mathrm{Ca}^{2+}\right]_{\mathrm{o}}$ and $0.1 \mathrm{MPa}$ pressure (for a more developed insight, see later Table 1). Thus, for example, the saturated response of $E_{1}$ at $10.1 \mathrm{MPa}$ and $4 \mathrm{mM}\left[\mathrm{Ca}^{2+}\right]_{\mathrm{o}}$ decreased by approximately $56 \%(p<0.01, n=6)$ compared to $4 \mathrm{mM}\left[\mathrm{Ca}^{2+}\right]_{0}$ at control pressure. Such a result may be the consequence of either a decrease in the fraction of synaptic resources (SR) used by $E_{1}$ (probably because of impaired $\mathrm{Ca}^{2+}$ entry into the terminals without a modification of SR), or a general decrease of SR dictating reduction of the $E_{1}$ fraction, or from both.

\section{EMPIRICAL ASSESSMENT OF SYNAPTIC RESOURCES AT DIFFERENT PRESSURES AND $\left[\mathrm{Ca}^{2+}\right]_{0}$}

As a first approximation for the SR size under different conditions, we adopted a simplified empirical estimation. We activated the MPP with trains of five identical stimuli at frequency of $50 \mathrm{~Hz}$, assuming that the inter-stimulus interval $(20 \mathrm{~ms})$ and the total duration of the train $(100 \mathrm{~ms})$ are short enough to avoid replenishment of used vesicles to their release sites. Thus the sum of the slopes of the five consecutive fEPSPs $\left(E_{\mathrm{T}}\right)$ should represent the SR at that time. Normalization of $E_{\mathrm{T}}$ with respect to $E_{\mathrm{T}}$, the $E_{\mathrm{T}}$ of saturated release at $0.1 \mathrm{MPa}$ and $4 \mathrm{mM}\left[\mathrm{Ca}^{2+}\right]_{0}$, allowed comparing SR under different conditions. Since $E_{\mathrm{T}}$ represents the total resources of the synapse under each condition, we may also estimate how much of these resources are being used by the first fEPSP $\left(E_{1}\right)$. For this matter we calculated $P_{1}$, the proportion of $E_{\mathrm{T}}$ used by $E_{1}\left(P_{1}=E_{1} / E_{\mathrm{T}}\right)$.

Table 1 reveals several characteristics of the SRs: (a) at normal pressure $E_{\mathrm{T}}$ remains constant despite $\left[\mathrm{Ca}^{2+}\right]_{\mathrm{o}}$ increase from 2 to $4 \mathrm{mM}$; (b) an analogous $\left[\mathrm{Ca}^{2+}\right]_{\mathrm{o}}$ change at $\mathrm{HP}$ paradoxically reduces $E_{\mathrm{T}}$ by $17 \pm 12 \%$ $(n=6, p<0.02)$; (c) $E_{\mathrm{T}}$ at HP is remarkably reduced in comparison with control pressure $(n=6, p<0.01)$. These calculations also revealed changes in $P_{1}$ : (a) elevated $\left[\mathrm{Ca}^{2+}\right]_{0}$ at normal pressure increased $P_{1}$ by $27 \pm 19 \%(n=6, p<0.01)$; (b) similar $\left[\mathrm{Ca}^{2+}\right]_{0}$ change at HP enhanced $P_{1}$ by $46 \pm 21 \%(n=6, p<0.005)$. Neither the $P_{1}$ for the same $\left[\mathrm{Ca}^{2+}\right]_{\mathrm{o}}$ at different pressures, nor the $\Delta P_{1}$ generated by raising $\left[\mathrm{Ca}^{2+}\right]_{0}$ were statistically significant between control and $\mathrm{HP}(n=6$, ANOVA).

We conclude that high $\left[\mathrm{Ca}^{2+}\right]_{\mathrm{o}}$ saturated synaptic responses by similar relative amount at control and $\mathrm{HP}$. But, the saturation level of $E_{1}$ at $\mathrm{HP}\left(E_{1} / E_{\mathrm{T}}{ }^{\prime}\right)$ was significantly lower than that at $0.1 \mathrm{MPa}$. This finding was correlated with reduction of $P_{1}$ and $E_{\mathrm{T}}$ at $\mathrm{HP}$, suggesting that some of the normal SR became unavailable at HP.

\section{HIGH $\left[\mathrm{Ca}^{2+}\right]_{0}$ INCREASES PAIRED-PULSE DEPRESSION UNDER CONTROL AND HP CONDITIONS}

The above assessment of SR status showed reduction of the estimated $\mathrm{SR}$ at $\mathrm{HP}$ whereas change in $\left[\mathrm{Ca}^{2+}\right]_{0}$ was not effective. Paired-pulse protocols normally allow the study of short-term synaptic plasticity, namely paired-pulse-facilitation (PPF) or paired-pulse-depression (PPD). By comparing the strength (slope) of the second fEPSP $\left(E_{2}\right)$ with respect to $E_{1}$ we can also estimate the proportion of $E_{\mathrm{T}}$ used by subsequent $E_{\mathrm{i}}$ for the two responses. In a previous study (Talpalar and Grossman, 2003) we showed that under control conditions of $\left[\mathrm{Ca}^{2+}\right]_{\mathrm{o}}$ and pressure, the MPP input displayed variable plasticity

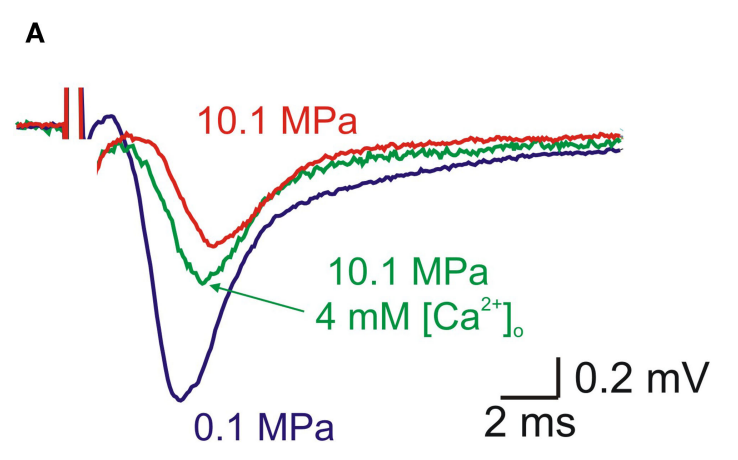

FIGURE 2 | High $\left[\mathrm{Ca}^{2+}\right]_{0}$ partially antagonizes HP depression of single MPP fEPSP. (A) fEPSPS, recorded at the inner dendritic area of the dentate gyrus, showing the effects of pressure $(0.1,5.1,10.1 \mathrm{MPa})$ at $2 \mathrm{mM}\left[\mathrm{Ca}^{2+}\right]_{\mathrm{o}^{\prime}}$ and the partial restoration of fEPSPs at HP by $4 \mathrm{mM}\left[\mathrm{Ca}^{2+}\right]_{0}$. (B) Statistical analysis of the

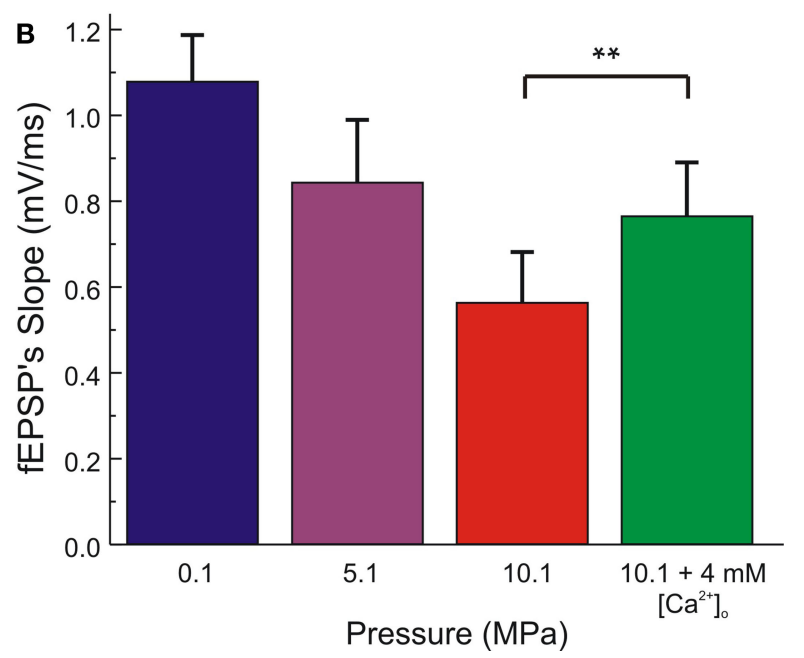

above experiments. fEPSPs are depressed in a pressure-dependent manner. At 10.1 MPa the fEPSP's slope is significantly increased at $4 \mathrm{mM}\left[\mathrm{Ca}^{2+}\right]_{\circ}$ $(p<0.0001, n=8)$. Further increasing $\left[\mathrm{Ca}^{2+}\right]_{0}$ to $6 \mathrm{mM}$ paradoxically resulted in reduction of fEPSP's slopes $(p<0.05, n=2)$. Scatter bars indicate mean \pm SE. 
depending on the duration of the inter-stimulus interval (ISI): ISIs of $<30 \mathrm{~ms}$ produced pure PPD $\left(E_{2} / E_{1}<1\right)$ while ISIs of $35-80 \mathrm{~ms}$ produced a small $5 \% \mathrm{PPF}\left(E_{2} / E_{1}>1\right)$. HP reduced PPD at short ISIs, and increased PPF of longer ISIs (Talpalar and Grossman, 2003), suggesting that synaptic release of $E_{1}$ was reduced shifting away from saturation. These observations were reproduced in the present set of experiments, in which 10.1 MPa pressure reduced PPD at the 10-20 ms ISIs and increased PPF at the 40-120 ms ISIs (Figure 3A). In addition, we compared the effect of raising $\left[\mathrm{Ca}^{2+}\right]_{\mathrm{o}}$ on similar paired-pulse modulation at control and HP.

Raising $\left[\mathrm{Ca}^{2+}\right]_{0}$ from $2 \mathrm{mM}$ to $4 \mathrm{mM}$ at normal pressure increased PPD (20 ms ISI) from $0.76 \pm 0.08$ to $0.58 \pm 0.08(n=6, p<0.01)$. At $10.1 \mathrm{MPa}$, similar change of $\left[\mathrm{Ca}^{2+}\right]_{0}$ increased $E_{1}$ by approximately $20 \%$ and relatively reduced $E_{2}$, consequently increasing PPD and reducing PPF (Figure 3A). For example, PPD at $20 \mathrm{~ms}$ ISI increased from $0.98 \pm 0.11$ at $2 \mathrm{mM}\left[\mathrm{Ca}^{2+}\right]_{0}$ to $0.61 \pm 0.07$ at $4 \mathrm{mM}\left[\mathrm{Ca}^{2+}\right]_{0}$ (by $36 \pm 7 \%, n=6, p<0.01$ ).

The increase of PPD by raising $\left[\mathrm{Ca}^{2+}\right]_{0}$ at $\mathrm{HP}$ was not statistically different from that produced at $0.1 \mathrm{MPa}$ (ANOVA, $n=6$ ). Table 2 summarizes the combined effects of $\left[\mathrm{Ca}^{2+}\right]_{0}$ and pressure on single, and paired-pulse fEPSPs.

Table 1 | Estimation of $E_{\mathrm{T}}(\mathrm{SR})$ and $P_{1}$ for single fEPSPs under various conditions.

\begin{tabular}{|c|c|c|c|c|}
\hline \multirow[b]{2}{*}{ Pressure } & \multicolumn{2}{|c|}{$2 \mathrm{mM}\left[\mathrm{Ca}^{2+}\right]_{0}$} & \multicolumn{2}{|c|}{$4 \mathrm{mM}\left[\mathrm{Ca}^{2+}\right]_{0}$} \\
\hline & $P_{1}$ & $E_{\mathrm{T}}$ & $P_{1}$ & $E_{\mathrm{T}}$ \\
\hline $0.1 \mathrm{MPa}$ & $0.35 \pm 0.11$ & $1.03 \pm 0.37$ & $0.44 \pm 0.1 \S$ & $1 \pm 0.23\left(E_{\mathrm{T}}^{\prime}\right)$ \\
\hline $10.1 \mathrm{MPa}$ & $0.27 \pm 0.04$ & $0.64 \pm 0.09 * *$ & $0.39 \pm 0.07 \S$ & $0.53 \pm 0.1^{*},{ }^{* *}$ \\
\hline
\end{tabular}

$P_{1}$ at HP was calculated using the $E_{T}$ for their respective conditions. Mean $\pm S E$, $n=6 . \delta p<0.01$ with respect of its respective control pressure; ${ }^{*} p<0.02, E_{T}$ is significantly smaller (17\%) at constant HP and increased $\left[\mathrm{Ca}^{2+}\right]_{o^{\prime}} n=6$; ${ }^{* *} p<0.01$, $H P$ significantly reduces $E_{T}$ with respect to control pressure.
For easier comparison, all the values of $E$ were normalized with respect to the largest $E_{1}$, obtained under $0.1 \mathrm{MPa}$ and $4 \mathrm{mM}\left[\mathrm{Ca}^{2+}\right]_{\mathrm{o}}$ conditions. It should be noted that at $0.1 \mathrm{MPa}$, although the amount of PPD is greater at $4 \mathrm{mM}$ than at $2 \mathrm{mM}\left[\mathrm{Ca}^{2+}\right]_{\mathrm{o}}$, the size of $E_{2}$ was not statistically different for these two conditions. Under HP and regular $\left[\mathrm{Ca}^{2+}\right]_{0}$ conditions, reduction of $E_{1}(>50 \%)$ was followed by an increase of $E_{2} / E_{1}$ suggesting that $E_{2}$ was utilizing a fraction of SR that was not available to $E_{1}$. In contrast, raising $\left[\mathrm{Ca}^{2+}\right]_{0}$ at $\mathrm{HP}$ increased $E_{1}$ by $20 \%$ but produced an $E_{2}$ that was smaller by $24 \pm 8 \%$ $(p<0.05, n=6)$ than $E_{2}$ at $2 \mathrm{mM}\left[\mathrm{Ca}^{2+}\right]_{0}^{2}$. These observations suggest that the SR is more limited at $\mathrm{HP}$ than at $0.1 \mathrm{MPa}$. Thus, high $\left[\mathrm{Ca}^{2+}\right]_{\mathrm{o}}$ increases $E_{1}$ while keeping $E_{2}$ unchanged at control pressure, whereas it increases $E_{1}$ at the expenses of $E_{2}$ at HP. As noted above the synaptic responses can be modulated by pressure and $\left[\mathrm{Ca}^{2+}\right]$. We hypothesized that an identical $E_{1}$, obtained under different conditions may yield dissimilar paired-pulse modulation and thus may yield new insight into the availability of SR. To that goal, we compared paired-pulse plasticity under two conditions that produced similar $E_{1}$ : increasing $\left[\mathrm{Ca}^{2+}\right]_{0}$ to $4 \mathrm{mM}$ at $10.1 \mathrm{MPa}$ and decompressing to $5.1 \mathrm{MPa}$ at $2 \mathrm{mM}\left[\mathrm{Ca}^{2+}\right]_{0}$. Despite the similar $E_{1}$, which increase by about $20 \%$ (compared to $10.1 \mathrm{MPa}-2 \mathrm{mM}\left[\mathrm{Ca}^{2+}\right]_{\mathrm{o}}$ condition) during changes in both variables, the relative size of $E_{2}$ differ greatly: $\mathrm{PPF}$ is present at ISIs $>30 \mathrm{~ms}$ at $5.1 \mathrm{MPa}$, while only pure PPD is evident at $4 \mathrm{mM}$ $\left[\mathrm{Ca}^{2+}\right]_{0}-10.1 \mathrm{MPa}$ (Figure 3B). These results suggest again that the SR is more limited at HP. Other possibility could be less effective summation of $\left[\mathrm{Ca}^{2+}\right]_{i}$ due to reduced entry at the highest pressure.

\section{DYNAMICS OF SYNAPTIC RESOURCES DURING SHORT TRAIN STIMULATION}

Synaptic activity at various frequencies leads to time-dependent changes in the availability of SR resulting either in FDD or frequency-dependent facilitation (FDF) (Tsodyks and Markram, 1997). Most of the mechanisms responsible for this modulation are presynaptic. Sustained action potentials firing, may initiate

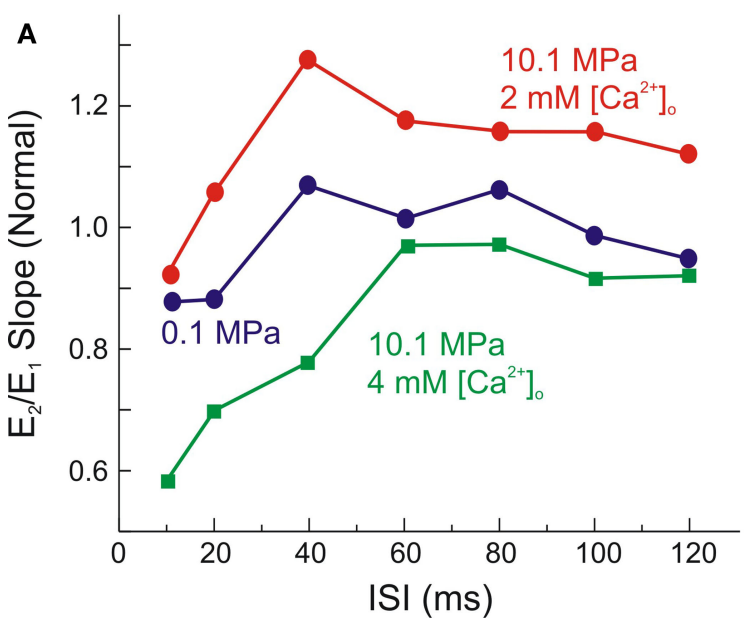

FIGURE 3 | High [ $\left.\mathrm{Ca}^{2+}\right]_{0}$ promotes paired-pulse-depression of MPP fEPSPs under HP. (A) Single experiment shows the antagonistic effect of high (4 mM) $\left[\mathrm{Ca}^{2+}\right]_{0}$ on $\mathrm{HP}(10.1 \mathrm{MPa})$ paired-pulse modulation. At $10.1 \mathrm{MPa}$ the initial phase of paired-pulse-depression (PPD) was attenuated, while the later paired-pulse-facilitation (PPF) was increased. Increased $\left[\mathrm{Ca}^{2+}\right]_{0}$ at HP partially

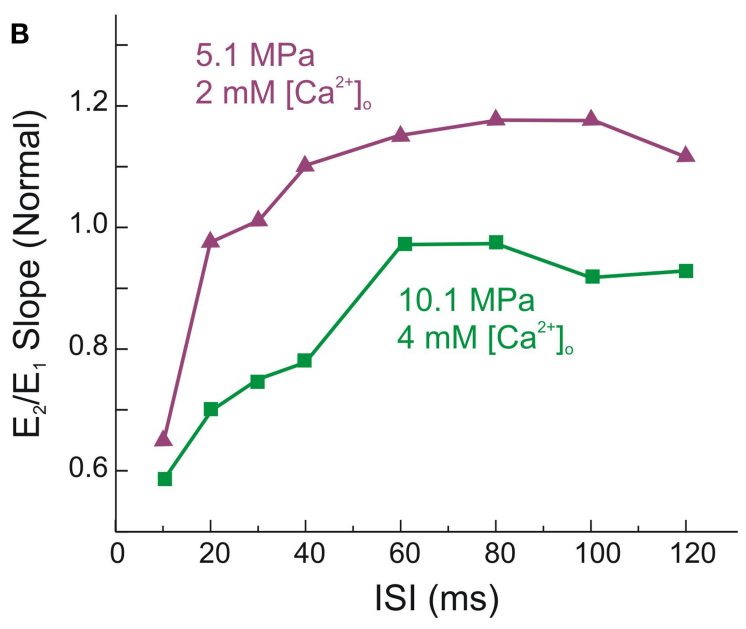

restored the slope of $E_{1}$, but increased PPD for short ISI and abolished the later phase of PPF for ISI 35-120 ms. (B) Comparison between PPM at 5.1 MPa (2 mM $\left.\left[\mathrm{Ca}^{2+}\right]_{0}\right)$ and $10.1 \mathrm{MPa}\left(4 \mathrm{mM}\left[\mathrm{Ca}^{2+}\right]_{0}\right)$. Note that $E_{1}$ under these two conditions is almost equal; however PPD is much greater under the latter condition. 
multivesicular release that facilitates the responses (Foster and Regehr, 2004) while the rates of vesicle docking, exocytosis, and replenishment determine the synaptic decay (Fernandez-Alfonso and Ryan, 2004). HP decreases the use of SR by single events $\left(E_{1}\right)$, reduces the sum of five fEPSPs at $50 \mathrm{~Hz}\left(E_{\mathrm{T}}\right)$, and modulates PPF/PPD.

These observations suggest that HP reduces also the availability of SR. We suspected that these changes result from slowed SR dynamics (see the mathematical parameters expressing the kinetics of the synaptic response in the paragraph below). To assess SR dynamics, we analyzed the course of five stimuli trains at $50 \mathrm{~Hz}$ under various conditions (Figures 4A,C). Under control conditions of $0.1 \mathrm{MPa}$ and $2 \mathrm{mM}\left[\mathrm{Ca}^{2+}\right]_{\mathrm{o}}$ stimulation at $50 \mathrm{~Hz}$ generated only PPD (between $E_{1}-E_{2}$ ) as part of the general exponential FDD, observed at $E_{2-5}$ (Figures $4 \mathbf{A}, \mathbf{B}$; see also Talpalar and Grossman,
2003). Increasing $\left[\mathrm{Ca}^{2+}\right]_{\mathrm{o}}$ from $2 \mathrm{mM}$ to $4 \mathrm{mM}$ at atmospheric pressure resulted in enhanced FDD, exhibiting shorter time constant of decay and reduction of the asymptotic level of the exponent compared with controls (Figure 4B, note that the responses in the train were normalized with respect to $E_{1}$ in each train). Compression to $10.1 \mathrm{MPa}$ keeping $2 \mathrm{mM}\left[\mathrm{Ca}^{2+}\right]_{0}$ reduced PPD, i.e., increased the component of PPF (as in Figure 3 ) and accelerated FDD during $E_{2-5}$ (Figures $4 \mathrm{C}, \mathbf{D}$ ). Raising $\left[\mathrm{Ca}^{2+}\right]_{0}$ to $4 \mathrm{mM}$ at $\mathrm{HP}$ increased $E_{1}$ by $20 \%$, abolished any sign of PPF and namely returned the system to a "pure" PPD mode, with even faster exponential decay to a lower asymptotic level of FDD (Figure 4D).

The decay rates of the five stimuli train and the $E_{5} / E_{1}$ ratios obtained at $4 \mathrm{mM}\left[\mathrm{Ca}^{2+}\right]_{\mathrm{o}}$ under control and $\mathrm{HP}$ conditions were not significantly different from each other (Figure 5A).

Table 2 | Effects of pressure and $\left[\mathrm{Ca}^{2+}\right]_{o}$ on single and paired fEPSPs at $20 \mathrm{~ms}$ ISI.

\begin{tabular}{|c|c|c|c|c|c|c|}
\hline \multirow[b]{2}{*}{ Pressure } & \multicolumn{3}{|c|}{$2 \mathrm{mM}\left[\mathrm{Ca}^{2+}\right]_{\mathrm{o}}$} & \multicolumn{3}{|c|}{$4 \mathrm{mM}\left[\mathrm{Ca}^{2+}\right]_{0}$} \\
\hline & $E_{1}$ & $E_{2}$ & $E_{2} / E_{1}$ & $E_{1}$ & $E_{2}$ & $E_{2} / E_{1}$ \\
\hline $10.1 \mathrm{MPa}$ & $0.41 \pm 0.09$ & $0.40 \pm 0.09$ & $0.98 \pm 0.11$ & $0.49 \pm 0.09$ & $0.30 \pm 0.08$ & $0.61 \pm 0.07$ \\
\hline
\end{tabular}

Values display fEPSPs' slopes normalized with respect to $E_{1}$ at $0.1 \mathrm{MPa}$ and $4 \mathrm{mM}\left[\mathrm{Ca}^{2+}\right]_{o^{\prime}} n=6$ for $0.1 \mathrm{MPa}, n=8$ for $10.1 \mathrm{MPa}$.

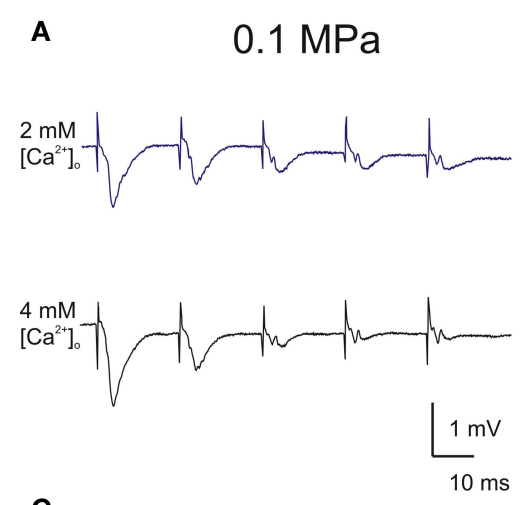

C

$10.1 \mathrm{MPa}$

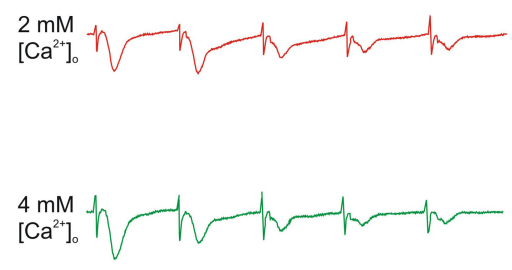

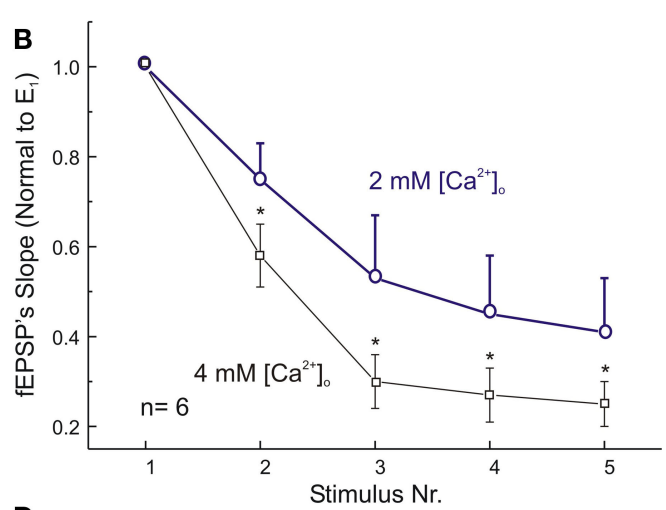

D

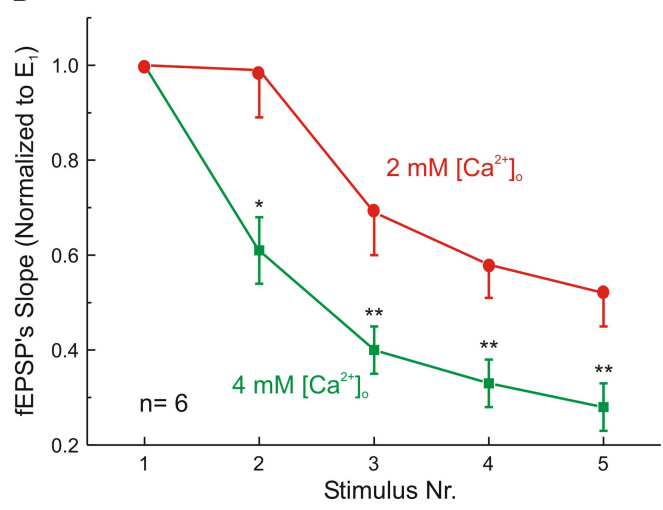

FIGURE 4 | High $\left[\mathrm{Ca}^{2+}\right]_{0}$ increases frequency-dependent-depression (FDD) at atmospheric pressure. Left: Dendritic recordings showing the effect of $\left[\mathrm{Ca}^{2+}\right]_{0}$ on trains of $5 \mathrm{fEPSPs}(50 \mathrm{~Hz})$ at pressure of $0.1 \mathrm{MPa}(\mathbf{A})$ and $10.1 \mathrm{MPa}$ (C). Calibration bars are the same for both conditions. Right: Statistical analysis of $\mathrm{FDD}$ at $50 \mathrm{~Hz}$. Each $E_{\mathrm{x}}$ was normalized with respect to its $E_{1}$ at its corresponding condition of $\left[\mathrm{Ca}^{2+}\right]_{\circ}$ and pressure. Effect of $\left[\mathrm{Ca}^{2+}\right]_{\circ}$ on FDD at pressure of $0.1 \mathrm{MPa}$ (B) and at $10.1 \mathrm{MPa}$ (D). ${ }^{*} p<0.05$,

${ }^{*} p<0.01$ depict statistical difference between stimuli at $2 \mathrm{mM}$ and $4 \mathrm{mM}\left[\mathrm{Ca}^{2+}\right]_{\circ}$ (independent $t$-test). All graphs display means $\pm \mathrm{SE}$ ( $n=6$ for each condition). 


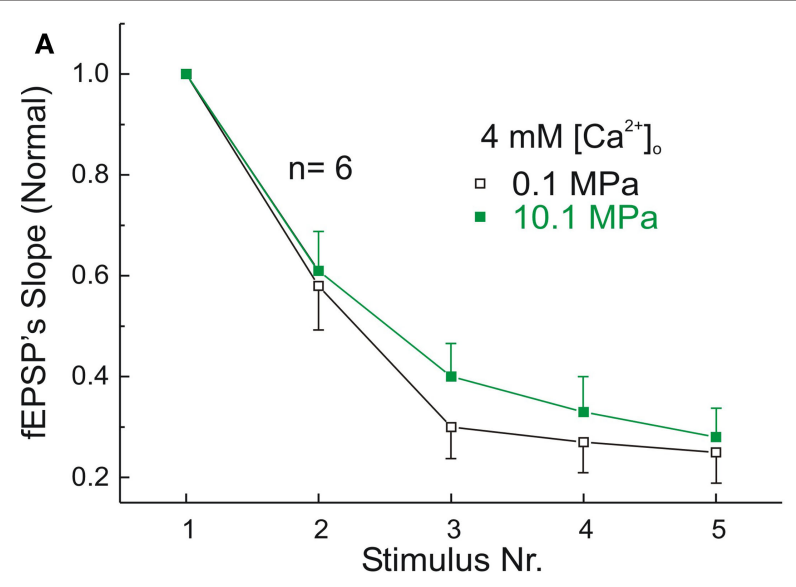

FIGURE 5 | Effect of pressure on the dynamics of MPP's FDD. (A) Similar FDD is induced by $4 \mathrm{mM}\left[\mathrm{Ca}^{2+}\right]_{0}$ at pressures of $0.1 \mathrm{MPa}$ and $10.1 \mathrm{MPa}$. $E_{\mathrm{x}}$ were normalized with respect to their corresponding $E_{1}$ ( $n=6$ for each condition; differences at each stimulus were not statistically significant).

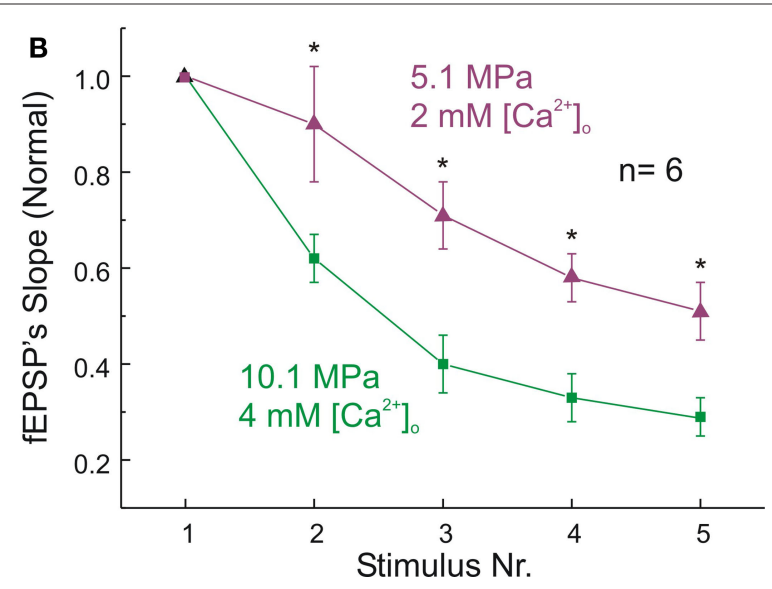

(B) FDD is more significant at $10.1 \mathrm{MPa}-4 \mathrm{mM}\left[\mathrm{Ca}^{2+}\right]_{0}$ than at $5.1 \mathrm{MPa}-2 \mathrm{mM}\left[\mathrm{Ca}^{2+}\right]_{\mathrm{o}^{\prime}}\left(n=6\right.$; $\left.{ }^{*} p<0.05\right)$. Note that larger FDD occurs at 10.1 MPa despite of the similarity of $E_{1}$ under both conditions. All graphs show means \pm SE.
These similar dynamics were observed despite the significant reduction of $E_{\mathrm{T}}$ and the difference in saturation levels of $E_{1}$ at increased $\left[\mathrm{Ca}^{2+}\right]_{\mathrm{o}}$ between the two pressure conditions.

Likewise the analysis of paired-pulse fEPSPs under two different conditions that generate similar E1, we compared also FDD (Figure 3B). An increase of $E_{1}$ by $\approx 20 \%$ with respect to $E_{1}$ at 10.1 MPa pressure and $2 \mathrm{mM}\left[\mathrm{Ca}^{2+}\right]_{\mathrm{o}}$ is brought about by either $4 \mathrm{mM}\left[\mathrm{Ca}^{2+}\right]_{\mathrm{o}}$ or decompression to $5.1 \mathrm{MPa}$. However, the FDD induced by $10.1 \mathrm{MPa}$ and $4 \mathrm{mM}\left[\mathrm{Ca}^{2+}\right]_{\mathrm{o}}$ was significantly faster than the FDD observed at 5.1 MPa and $2 \mathrm{mM}\left[\mathrm{Ca}^{2+}\right]_{\mathrm{o}}$ (Figure 5B). This difference suggests that $10.1 \mathrm{MPa}$ may indeed further reduce $\mathrm{Ca}^{2+}$-entry (Gilman et al., 1986; Grossman and Kendig, 1990) in comparison to $5.1 \mathrm{MPa}$, since the increased $\mathrm{Ca}^{2+}$-driving force at 10.1 MPa was not sufficient to induce additional synaptic release by $E>1$ when $E_{1}$ was already saturated at a subnormal level. Then, increasing $\left[\mathrm{Ca}^{2+}\right]_{0}$ was followed by enhancement of $E_{1}$ and by a relative reduction of the following $E_{2}-E_{5}$ (see above) while keeping approximately constant the relationship $E_{5} / E_{1}$.

The above calculations compared how pressure and $\left[\mathrm{Ca}^{2+}\right]_{\text {o }}$ modulated the relationship between $E_{2-5}$ with respect to $E_{1}$ under similar conditions. These calculations may serve for estimation of the utilization of $E_{5}$ fraction when compared to $E_{\mathrm{T}}$ (approximately SR) under different conditions, and then to compare it with $E_{\mathrm{T}}$, the maximal available SR.

Table 3 compares the relationship $E_{5} / E_{1}$ under various conditions indicating the degree of depression at the end of the train. $E_{1}$ and $E_{5}$ values were normalized with respect to the largest $E_{1}$ when $S R$ is maximal at $0.1 \mathrm{MPa}$ and $4 \mathrm{mM}\left[\mathrm{Ca}^{2+}\right]_{0}$. Using this normalization clearly demonstrates again (in addition to Figures 4B,D in which the normalization is to $E_{1}$ for each condition) that the amount of $\operatorname{FDD}\left(E_{5} / E_{1}\right)$ is quite similar for both pressure conditions but it is significantly larger for $4 \mathrm{mM}\left[\mathrm{Ca}^{2+}\right]_{\text {o }}$.

As described above (Table 1) HP reduced $E_{1}$ and $E_{\mathrm{T}}$ (the sum of $E_{1-5}$ ) but elevated $\left[\mathrm{Ca}^{2+}\right]_{\mathrm{o}}$ affected largely $E_{1}$ and much less $E_{\mathrm{T}}$. This difference suggests that $E_{\mathrm{T}}$ is mainly pressure-sensitive whereas $E_{\mathrm{n}}$ is determined by both $\mathrm{HP}$ and $\left[\mathrm{Ca}^{2+}\right]_{0}$. In order to further elucidate these findings, we calculated the utility factor $\left(P_{\mathrm{n}}\right)$; the portion of SR used by each $E_{\mathrm{n}} . P_{\mathrm{n}}$ is calculated as the ratio of $E_{\mathrm{n}} / E_{\mathrm{T}}$ for each condition. Figure $6 \mathrm{~A}$ depicts the values of $P_{1}-P_{5}$ at 2 and $4 \mathrm{mM}$ $\left[\mathrm{Ca}^{2+}\right]_{0}$ at $0.1 \mathrm{MPa}$. It should be noted that the increased $P_{1}$ at $4 \mathrm{mM}$ $\left[\mathrm{Ca}^{2+}\right]_{0}$ was at the expenses of later fEPSPs because the estimated $E_{\mathrm{T}}$ was similar for these two $\left[\mathrm{Ca}^{2+}\right]_{0}$. This excluded the possibility of changes in SR depletion and replenishment. At HP (Figure 6B), an identical increase in $\left[\mathrm{Ca}^{2+}{ }_{0}\right.$ produces a similar enhancement of $P_{1}$ and redistribution of the rest of $P_{\mathrm{x}}$. By normalization of $P_{\mathrm{n}}$ with respect to $E_{\mathrm{T}}$ ' $\left(0.1 \mathrm{MPa}-4 \mathrm{mM}\left[\mathrm{Ca}^{2+}\right]_{\mathrm{o}}\right)$ we may estimate how much of the maximally available $\mathrm{SR}$ is used by each $E_{\mathrm{n}}$ under the different conditions (Figure 6C).

Comparison of HP effect at $2 \mathrm{mM}\left[\mathrm{Ca}^{2+}\right]_{\mathrm{o}}$, showed that $10.1 \mathrm{MPa}$ significantly reduced $P_{1}$ and $P_{2}$ alone $(p<0.01$ for each, independent $t$-test, $n=6$ ), while the size of the following $P_{3-5}$ were not significantly different from control pressure. In contrast, when comparing pressure effects at high $\left[\mathrm{Ca}^{2+}\right]_{\mathrm{o}}$, all $P_{\mathrm{n}}$ values were significantly reduced at $\mathrm{HP}(p<0.05$ for all the events, $n=6$ for each condition; Figures 5A and 6C).

In sum, at atmospheric pressure all the described dynamics occurred while $E_{\mathrm{T}}$ seemed to be constant. But at HP the $E_{\mathrm{T}}$ was severely diminished in a pressure-dependent manner.

\section{TSODYKS-MARKRAM MODEL: SYNAPTIC RESOURCES AND THEIR DYNAMIC UTILIZATION UNDER THE EXPERIMENTAL CONDITIONS}

Empirical results suggest: (a) that SR and the utilization of these resources by individual synaptic inputs are reduced in a pressuredependent manner; (b) that varying $\left[\mathrm{Ca}^{2+}\right]_{0}$ at constant pressure changes the relative utilization of SR but not the absolute value of SR. We employed a standard mathematical model, originally proposed by Tsodyks and Markram (1997), to estimate the relative changes in dynamics of the processes. This model captures the frequencydependent modulation of fEPSPs upon repetitive stimulation, by describing the temporal evolution of the amount of the readily available synaptic resources $r$, and of their fraction $u$, recruited at each stimulus for neurotransmission (see Materials and Methods). 
Table 3 | Effects of pressure and $\left[\mathrm{Ca}^{2+}\right]_{\mathrm{o}}$ on fEPSPs produced during five stimuli trains at $50 \mathrm{~Hz}$.

\begin{tabular}{|c|c|c|c|c|c|c|}
\hline \multirow[b]{2}{*}{ Pressure } & \multicolumn{3}{|c|}{$2 \mathrm{mM}\left[\mathrm{Ca}^{2+}\right]_{0}$} & \multicolumn{3}{|c|}{$4 \mathrm{mM}\left[\mathrm{Ca}^{2+}\right]_{0}$} \\
\hline & $E_{1}$ & $E_{5}$ & $E_{5} / E_{1}$ & $E_{1}$ & $E_{5}$ & $E_{5} / E_{1}$ \\
\hline $10.1 \mathrm{MPa}$ & $0.41 \pm 0.09$ & $0.21 \pm 0.03$ & $0.51 \pm 0.16$ & $0.56 \pm 0.09$ & $0.16 \pm 0.03$ & $0.28 \pm 13^{* *}$ \\
\hline
\end{tabular}

Values display fEPSPs' slopes normalized with respect to $E_{1}$ at $0.1 \mathrm{MPa}$ and $4 \mathrm{mM}\left[\mathrm{Ca}^{2+}\right]_{0} . n=6$ for $0.1 \mathrm{MPa}, n=8$ for $10.1 \mathrm{MPa}$. Significance level for the $E_{5} / E_{1}$ between low and high $\left[\mathrm{Ca}^{2+}\right]_{0}$ at the corresponding pressure is ${ }^{*} p=0.07$ and ${ }^{*} p<0.001$.

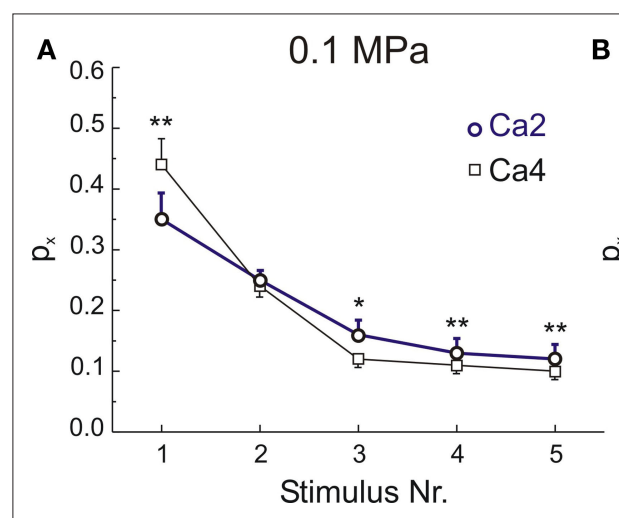

FIGURE 6 | Effects of $\left[\mathrm{Ca}^{2+}\right]$ on dynamics of MPP synaptic variables during $50 \mathrm{~Hz}$ stimulation at two different pressures. (A) High $\left[\mathrm{Ca}^{2+}\right]_{0}$ significantly increases $P_{1}$, but it significantly reduces the $P_{3.5}$ with respect to their respective controls. (B) At 10.1 MPa high $\left[\mathrm{Ca}^{2+}\right]_{0}$ also increases $P_{1}$ at expenses of $P_{2-5}$ denoting reduction of $E_{\mathrm{T}}$ Graphs display means $\pm \mathrm{SE}, n=6$ for each condition ${ }^{*} p<0.05$ and ${ }^{*} p<0.01$ (paired $t$-test). (C) Differential effects of
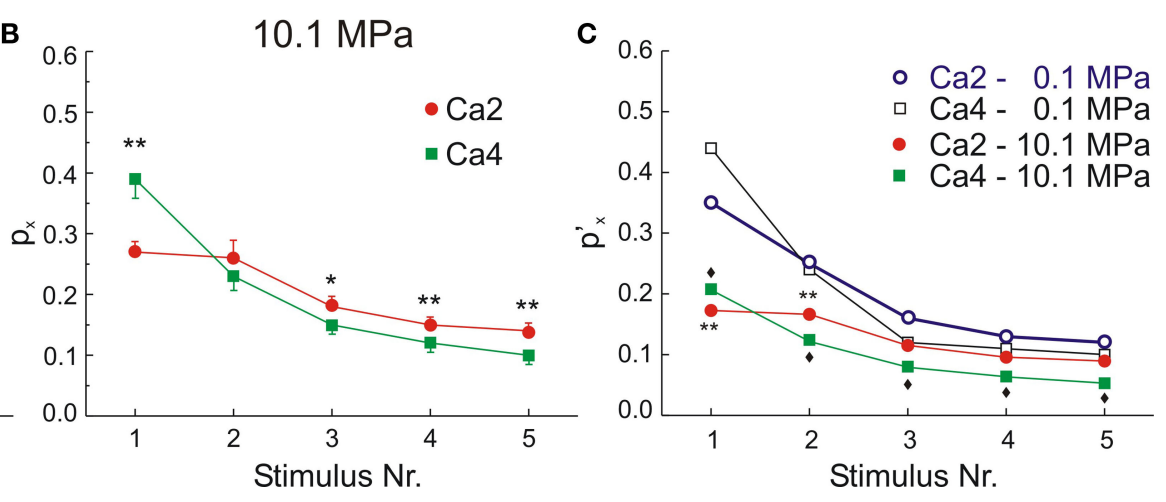

The model is fully specified by (i) the time constant associated to the recovery from depression $D$, (ii) the time constant associated to the recovery from facilitation $F$, (iii) the phenomenological description of the probability of release $U$, and (iv) the maximal synaptic efficacy $A$, that captures both the postsynaptic receptor density and conductance as well as the presynaptic size of the readily releasable neurotransmitter pool.

Regardless of the experimental condition, the fit performance of the model was generally satisfactory in describing the experimental recordings. When its four free parameters were best-fitted to each of the 54 experiments (i.e., five fEPSP responses each), the relative root mean square error was below $4 \%$ in $45 / 54$ cases, and below $1 \%$ in $26 / 54$ cases. In addition, the statistical $\mathrm{X}^{2}$-test for assessing the goodness of the fit (Press et al., 1992) was passed in $38 / 54$ cases, even though the conditions for this test were unfavorable in terms of the degrees-of-freedom of the $\mathrm{X}^{2}$-distribution (i.e., difference between the number of data points and optimized model parameters, $5-4$, was small). Thus the model quantitatively captured the experimental data-set within the parameters range (mean \pm SD) $A \sim 3.06 \pm 3.05, U \sim 0.37 \pm 0.16, D \sim 200.6 \pm 130.2 \mathrm{~ms}$, and $F \sim 50 \pm 98.3 \mathrm{~ms}$. When the experimental conditions (e.g., $\left[\mathrm{Ca}^{2+}\right]_{\mathrm{o}}$, pressure, or both) changed, the fEPSP responses changed accordingly. In order to investigate which of the model parameters accounted for each experimental condition explored, we considered the best-fit performance as estimated by the $\mathrm{X}^{2}$-test, since this
$\left[\mathrm{Ca}^{2+}\right]_{0}$ and pressure on the dynamics of MPP synaptic variables. All the fractions were normalized with respect to $E_{\mathrm{T}}$ at control pressure and $4 \mathrm{mM}\left[\mathrm{Ca}^{2+}\right]_{\mathrm{o}^{\prime}}\left(E_{\mathrm{T}}{ }^{\prime}\right)$. The effect of $\left[\mathrm{Ca}^{2+}\right]_{0}$ and pressure on sequential Ps: $P_{1-2}$ display significant difference between $0.1 \mathrm{MPa}$ and $10.1 \mathrm{MPa}$ in control $\left[\mathrm{Ca}^{2+}\right]_{0}\left(n=6,{ }^{*} p<0.01\right)$. At high $\left[\mathrm{Ca}^{2+}\right]_{0}$ all Ps were significantly depressed by $10.1 \mathrm{MPa}(n=6, \bullet<0.05$ for all of them). SE bars have been omitted for the sake of clarity. takes into explicit account the number of free parameters. We then focused on finding the minimal set of model parameters that most likely were affected by the experimental condition. In the case (e.g.) of the change in $\left[\mathrm{Ca}^{2+}\right]_{0}$, data from the two conditions were simultaneously fitted (i.e., $5+5$ fEPSP responses). We then alternatively allowed one, two, three or all four parameters to change across the conditions, thus resulting in 5-8 free parameters. Ranking each fit performance on the basis of its $\mathrm{X}^{2}$-test score provided an explicit indication of the parameter(s) that most often appeared to result in a good fit, when changed.

From this systematic analysis, summarized in Table 4, we conclude that: (1) when $\left[\mathrm{Ca}^{2+}\right]_{0}$ is increased, $U$ is the parameter that is most sensitive to such a change, in agreement with the underlying biophysical interpretation of $U$ as the presynaptic release probability; (2) when the pressure alone is varied, $A$ is the parameter that is most sensitive to such a change, reminiscent of a change in the size of the readily-releasable pool and/or of postsynaptic excitability (see discussion).

In details, we found that the change in $\left[\mathrm{Ca}^{2+}\right]_{\mathrm{o}}$ from $2 \mathrm{mM}$ to $4 \mathrm{mM}$, decreased $A$ by $10 \%$ while increasing $U$ by $47 \%$. Only the change in $U$ was considered significant, on the basis of the parameters range indicated previously. Similar considerations apply when $U$ alone was allowed to change, resulting in a slightly worse root mean square error of $3.9 \%$, as expected, but an equally significant increase in $U$ of $\sim 30 \%$. 
Table 4 | Markram-Tsodyks model best-fit parameters for different conditions.

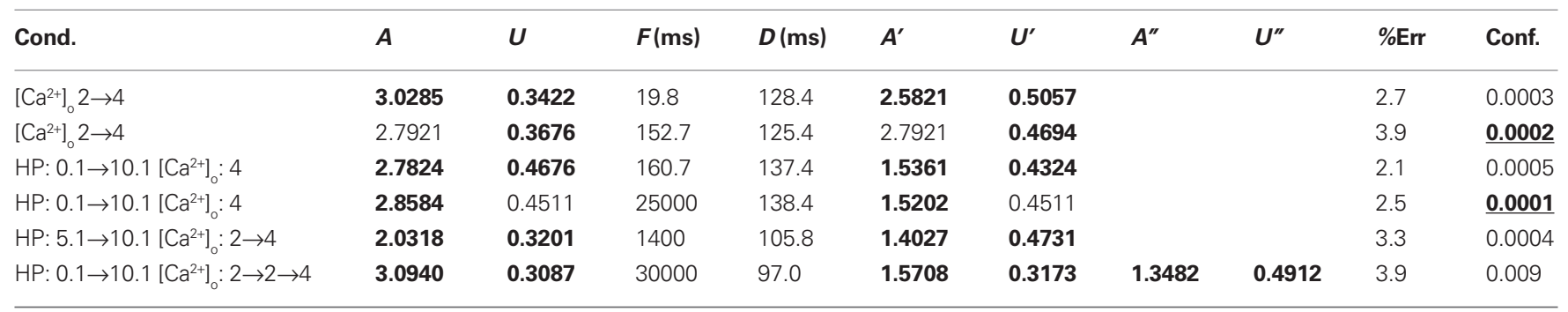

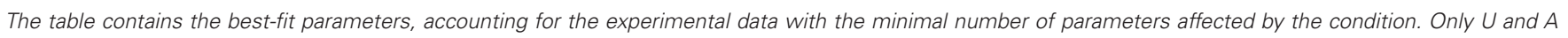

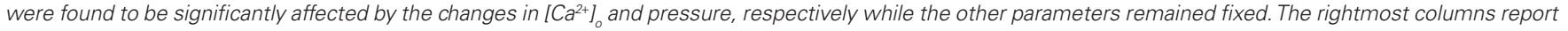

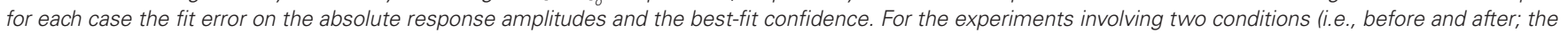

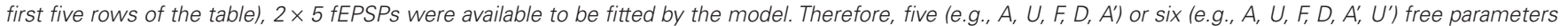

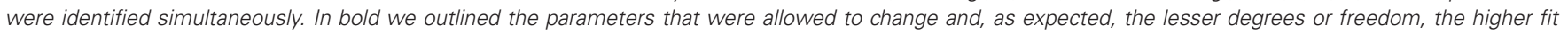
confidence (underlined).

For the other experiments, $3 \times 5$ fEPSPs were available to be fitted by the model, therefore requiring identifying eight (e.g., $A$, $U$, $F$, $D$, $\left.A^{\prime}, U^{\prime}, A^{\prime \prime}, U^{\prime \prime}\right)$ parameters.

The change in HP from 0.1 to $10.1 \mathrm{MPa}$, while keeping $\left[\mathrm{Ca}^{2+}\right]_{\mathrm{o}}$ fixed at $4 \mathrm{mM}$ (as in Figure 6A), caused $A$ to decrease by $45 \%$ while $U$ was unaffected (i.e., $-7 \%$ ). Similar conclusions could be drawn when only $A$ was allowed to change.

When HP was changed from 5.1 to $10.1 \mathrm{MPa}$ and simultaneously $\left[\mathrm{Ca}^{2+}\right]_{0}$ from 2 to $4 \mathrm{mM}$ (as in Figure 6B), A decreased significantly by $30 \%$ while $U$ increased by $48 \%$.

Finally, when HP was changed from 0.1 to $10.1 \mathrm{MPa}$, with $\left[\mathrm{Ca}^{2+}\right]_{\mathrm{o}}$ set first to $2 \mathrm{mM}$, and later to $4 \mathrm{mM}$, respectively (Figure 5B), $A$ first decreased by $50 \%$ and later remained unaffected $(-56 \%$ with respect to the initial $0.1 \mathrm{MPa}$ condition), while $U$ remained first unaffected $(+3 \%)$ and then increased by $60 \%$, confirming that $\left[\mathrm{Ca}^{2+}\right]_{0}$ affects $U$ while HP affects $A$.

\section{DISCUSSION}

The results reported in this work were collected under strict steadystate conditions for both pressure and temperature (see Materials and Methods). As reported previously (Talpalar and Grossman, 2003) the reduction of MPP synapse parameters is directly proportional to the applied pressure, but the full effect of pressure is quantified after stabilization. Under these conditions, the MPP synaptic responses remain stationary for a long period of time (i.e., up to $2 \mathrm{~h}$ at maximal pressure, $10.1 \mathrm{MPa}$ ) with no obvious run-down (see also Etzion and Grossman, 2000). Then, we confidently assume that the response is stable and not affected in a time-dependent manner by the pressure. The relatively long ( $1 \mathrm{~min}$ ) interval between subsequent stimulus trains apparently allows the replenishment of the RRP at all pressure conditions (we observed extremely small sample variance either at control or HP). We contemplated the possibility that the reduction of the single MPP fEPSP at HP may result also from a partial random "depletion" of its RRP, which was unable to recover its control size after synaptic release. But such kind of time-dependent depletion at HP may have produced a progressive and larger decline of single (not trains) fEPSP responses (sampled at $0.1 \mathrm{~Hz}$ ), that we did not see in the experiments.

Single-fiber stimulation of the MPP at $50 \mathrm{~Hz}$ during whole-cell recordings of granule cells in perinatal rat slices showed failure of discrete 10-20 pA synaptic events (Talpalar, 2002). Such experiments suggest that FDD results from progressive exhaustion of discrete components at axon branches, terminals or release sites. However, the modest effect of HP on axon terminals (input volley) compared with the effect on synaptic inputs (Etzion and Grossman, 2000; Talpalar and Grossman, 2003) makes it unlikely a predominant effect of pressure on axonal branches. Moreover, quantal analysis in crustacean neuromuscular synapses exposed to HP resulted in reduction of $p$ and $n$, and unchanged $q$, implying a pressure-dependent reduction of the release probability and a pressure-independent quantal size at the release sites.

The fact that synaptic responses elicited by the more challenging stimulation rate of $50-\mathrm{Hz}$ decay more or less like controls, and the coincident effect of pressure on different types of synapses, led us to favor the hypothesis that HP reduces the number of release sites and unveils a "modular" organization of the RRP consisting in "pressure-sensitive" and "pressure-resistant" modules rather than a random "depletion" of the RRP. This last possibility could not be totally excluded since the mechanisms underlying short-term plasticity are inconclusive. The use of the phenomenological model for short-term synaptic plasticity to fit the experimental responses is a first attempt at exploring whether pressure might influence other features and mechanisms underlying frequency-dependent synaptic depression.

The input/output consequences of a potential reduction of the RRP have been investigated earlier for different pressures, by examining granule cell firing in response to MPP stimulation (Talpalar and Grossman, 2004). Despite of the reduction in synaptic inputs, the output was conserved for stimulation frequencies below $25 \mathrm{~Hz}$, for which there is no difference between control and 10.1 MPa. For stimulation at higher frequencies $(50 \mathrm{~Hz})$, there was instead an increased excitability and loss of filter properties of the circuit. This may be likely attributed to a similar pressure-dependent effect on inhibitory synapses, leading to a proportional reduction in the inhibitory synaptic contributions from inhibitory interneurons.

\section{HP AND $\left[\mathrm{Ca}^{2+}\right]_{0}$}

This study has compared the use of SR by MPP synapses under various conditions of pressure and $\left[\mathrm{Ca}^{2+}\right]_{0}$. Increasing $\left[\mathrm{Ca}^{2+}\right]_{0}$ under both normal and HP conditions enhances MPP's single fEPSPs, $E_{1}$. Saturation of a single response was attained with $4 \mathrm{mM}\left[\mathrm{Ca}^{2+}\right]_{\mathrm{o}}$, whereas higher $\left[\mathrm{Ca}^{2+}\right]_{0}$ depressed $E_{1}$. This effect of $\left[\mathrm{Ca}^{2+}\right]_{0}$ is probably 
due to increase in $\mathrm{Ca}^{2+}$-entry at the terminals and consequently an increase of the probability of synaptic release. Thus, these results suggest that release by $E_{1}$ is unsaturated at control $\left[\mathrm{Ca}^{2+}\right]_{0}$ under both normal (Schneggenburger and Neher, 2000) and HP conditions (Golan and Grossman, 1992).

Under normobaric conditions the total synaptic release, $E_{\mathrm{T}}$, during five stimuli at $50 \mathrm{~Hz}$ was used as a first estimation of the SR. $E_{\mathrm{T}}$ did not change in the range of $2-4 \mathrm{mM}\left[\mathrm{Ca}^{2+}\right]_{\mathrm{o}}$, suggesting that $\left[\mathrm{Ca}^{2+}\right]_{\mathrm{o}}$ affects mainly the $P_{1}$, the proportion of $E_{\mathrm{T}}$ used by $E_{1}$. At 10.1-MPa pressure both, $E_{1}$ and $E_{\mathrm{T}}$ were significantly reduced in comparison with their normobaric controls. The effect of increasing $\left[\mathrm{Ca}^{2+}\right]_{0}$ at HP was similar to that at normal pressure.

The reduced $E_{1}$ was associated with conserved FDD. If FDD is generated by depletion of synaptic vesicles (Abrahamsson et al., 2005), these results may disagree with the hypothesis that stimulation at high frequency increases $\mathrm{Ca}^{2+}$ influx which accelerate vesiclerecycling rate (Wang and Kaczmarek, 1998).

Raising $\left[\mathrm{Ca}^{2+}\right]_{\mathrm{o}}$ at HP enhanced synaptic release, but its maximal effect only partially restored synaptic transmission (Grossman and Kendig, 1990; Golan and Grossman, 1992; Golan et al., 1994, 1995, 1996). Thus, synaptic release was saturated but at a subnormal level, i.e., reduced RRP (which represents the presynaptic component of the SR), and exhibited exponential FDD during stimulation at $50 \mathrm{~Hz}$. Similar to normal pressure, increasing $\left[\mathrm{Ca}^{2+}\right]_{\mathrm{o}}$ at $\mathrm{HP}$ enhanced $E_{1}$ concomitantly with faster rate of the FDD (Figure 4D). But FDD rates at high $\left[\mathrm{Ca}^{2+}\right]_{0}$ were not significantly different at both pressures (Figure 5A). Interestingly, when identical $E_{1}$ to that at $10.1 \mathrm{MPa}, 4 \mathrm{mM}\left[\mathrm{Ca}^{2+}\right]_{o}$ was obtained by partial decompression to $5.1 \mathrm{MPa}$ at $2 \mathrm{mM}\left[\mathrm{Ca}^{2+}\right]_{0}$, the FDD was reduced and its rate was slowed (Figure 5B). This indicates that similar to normal pressure, FDD is independent of $E_{1}$ initial size but depends on $\left[\mathrm{Ca}^{2+}\right]_{0}$.

Unexpectedly, higher $\left[\mathrm{Ca}^{2+}\right]_{0}$ further reduced SR at HP (see Figure 6B). The reduction of PPD and/or increase PPF at HP suggests that $E_{1}$ receded from saturation, probably by reduced $\mathrm{Ca}^{2+}$ entry, leaving a larger fraction of unused RRP, which may partially enhance $E_{2}$. In addition, the data provide strong evidence for pressure reduction of the RRP, independent of $\mathrm{Ca}^{2+}$-entry.

\section{$\mathrm{Ca}^{2+}$ DOMAINS AND ACTIVE ZONES}

One of the major mechanisms postulated for the effects of HP on CNS synaptic function is reduced synaptic release that has been shown in chromaffin cells (Heinemann et al., 1987) and supported by an increased facilitation at reduced $\left[\mathrm{Ca}^{2+}\right]_{0}$ mimicking $\mathrm{HP}$ effects (Talpalar and Grossman, 2003). Various lines of evidence suggest that HP impairs $\mathrm{Ca}^{2+}$-entry in protozoa (Otter and Salmon, 1979, 1985), brain synaptosomes (Gilman et al., 1986), and presynaptic terminals of crustacean synapses (Grossman and Kendig, 1990). Furthermore, detailed quantal analysis of crustacean neuromuscular synapses revealed that in all types of synapses HP depressed release (i.e., decreased quantal content, $m$ ) by reducing the number of active release sites $(n)$ with variable small effect on the probability of release $(p)$ depending on the type of the synapses (Golan et al., 1994, 1995, 1996). Similar quantal analysis for CNS and MPP synapses are not available. However, it is known that a combination of $\mathrm{N}$ - and $\mathrm{P} / \mathrm{Q}$-channels mediate synaptic release in the mice's MPP (Qian and Noebels, 2001). The facts that L-type $\mathrm{Ca}^{2+}$-currents were resistant to $40 \mathrm{MPa}$ pressure (Heinemann et al., 1987) while
$\mathrm{Ca}^{2+}$ spikes elicited by $\mathrm{P} / \mathrm{Q}$-channels were only minimally reduced at 10.1 MPa (Etzion and Grossman, 1999), suggest that N-type channels fraction is the likely target for HP depression. Though there is no information about HP effect on the kinetics of $\mathrm{N}$-type currents, the fact that they seem to be mechano-sensitive (Calabrese et al., 2002), and potentially highly pressure-sensitive in guinea pig cerebellar synapses (Etzion and Grossman, 2000) and frog neuromuscular junction (Grossman et al., 1991) strongly suggest their involvement also in HP effects on MPP synapses. If this is the case, saturation of MPP synaptic response at a subnormal level and occurrence of exponentially decaying FDD, combined with reduction of the RRP suggest a close functional dependence between the $\mathrm{N}$-type pressure-sensitive $\mathrm{Ca}^{2+}$-channels, and a specific portion of the RRP. In another words, a portion of the RRP seems to be dependent on a Ca-domain that is provided solely by $\mathrm{N}$-type channels (for a review see Oheim et al., 2006). This is also consistent with the effect of raising $\left[\mathrm{Ca}^{2+}\right]_{\mathrm{o}}$, which under both pressure conditions could increase $P_{\mathrm{n}}$ but not $E_{\mathrm{T}}$ whereas at HP increased $\mathrm{Ca}^{2+}$-entry through pressure-resistant channels could only partially enhance $E_{1}$ but not to restore release to control level. Moreover, these effects invoke the hypothesis that MPP synaptic strength may be based on a modular structure composed of different portions exclusively dependent on specific $\mathrm{Ca}^{2+}$-channels ( $\mathrm{N}$ type- $E_{\mathrm{T}}, \mathrm{P} / \mathrm{Q}$ type- $E_{\mathrm{T}}$, etc.), which at high $\left[\mathrm{Ca}^{2+}\right]_{\mathrm{o}}$ may behave as saturated pools.

CA1 hippocampal synapses (and possibly MPP synapses) activezones contain approximately 10 (2-27) docked vesicles (the RRP) and nearly 200 free "storage" vesicles (Schikorski and Stevens, 1997) of potentially releasable vesicles (Fernandez-Alfonso and Ryan, 2004) while each terminal contains between 1 (Schikorski and Stevens, 1997) and 2-4 active-zones (Geinisman, 1993). These morphological features are suggestive of synaptic modularity; namely, observed LTP in CA1 may increase RRP (number of active zones) and LTD, may decrease RRP (Bolshakov et al., 1997; Toni et al., 1999; Geinisman et al., 2001). However, it is unknown if these suggested changes in RRP fit with our proposed Ca-channel-type dependent modules. It is worth noticing that Tsodyks and Markram (1997) concluded, based on a theoretical model and experimental data, that once the synaptic depression rate is set, release probability (i.e., by the model parameter $U$ ) becomes the important factor in determining and fine-tuning the neural code, by shaping and redistributing the synaptic efficacy across subsequent responses (Markram and Tsodyks, 1996). Here we suggest that the size of the RRP, especially if it is modular may also play a crucial role in determining the communication between neurons, acting as an absolute amplification or attenuation factor (i.e., by the model parameter $A$ ) of synaptic transmission but leaving the relative EPSPs amplitudes relationship unaffected.

\section{GENERAL CONSIDERATIONS}

From a network point of view, a synapse composed of pressuresensitive and pressure-resistant modules, depending on their Ca-channel domains, may have adaptational advantages. In environmental conditions such as pressure or temperature (thermodynamic equivalents) a modular synapse will allow the maintenance of constant frequency-dependent properties (FDD). Consistently, Moser and Andersen (1994) showed that changes in temperature (within a moderate range) did not significantly disturb the behavior 
of animals and function of cortico-hippocampal areas. A reduced but "scaled" dynamic RRP, may be functionally relevant for conserving behavior at low energy cost (Talpalar and Grossman, 2006).

Reduction of the RRP size at HP (or cooling) may be useful for maintaining a behaviorally important defined pattern of synaptic transmission even if $\mathrm{Ca}^{2+}$ influx is impaired and vesicles retrieval is slowed down because of metabolic reasons. This mechanism may be particularly efficient for maintaining a physiological function if combined with postsynaptic boosting (Talpalar and Grossman, 2004, 2006). In fact, a HP reduced MPP input was shown to produce a normal firing pattern if activation does not exceed $25 \mathrm{~Hz}$, but shows the disadvantage of generating hyperexcitability with excessive stimulation at higher frequencies (Talpalar and Grossman, 2004, 2005).

In conclusion, these results support the hypothesis that portions of the MPP's RRP behave like separate synaptic modules that are dependent on $\mathrm{Ca}^{2+}$-entry through different channels. The utility of these module RRPs during stimulation at frequency can

\section{REFERENCES}

Abbott, L. F., Varela, J. A., Sen, K., and Nelson, S. B. (1997). Synaptic depression and cortical gain control. Science 275, 220-224.

Abrahamsson, T., Gustafsson, B., and Hanse, E. (2005). Synaptic fatigue at the naive perforant path-dentate granule cell synapse in the rat. J. Physiol. 569, 737-750.

Abraini, J. H. (1997). Inert gas and raised pressure: evidence that motor decrements are due to pressure per se and cognitive decrements due to narcotic action. Pflugers Arch. 433, 788-791.

Abraini, J. H., Ansseau, M., and Fetchali, T. (1993). Pressure-induced disorders in neurotransmission and spontaneous behavior in rats: an animal model of psychosis. Biol. Psychiatr. 34, 622-629.

Aravanis, A. M., Pyle, J.L., and Tsien, R.W. (2003). Single synaptic vesicles fusing transiently and successively without loss of identity. Nature 423, 643-647.

Bailey, C. H., and Chen, M. (1988). Morphological basis of short-term habituation in Aplysia. J. Neurosci. 8, 2452-2459.

Beck, H., Goussakov, I. V., Lie, A., Helmstaedter, C., and Elger, C. E. (2000). Synaptic plasticity in the human dentate gyrus. J. Neurosci. 20, 7080-7086.

Bennett, P. B., and Rostain, J. C. (2003). "The high pressure nervous syndrome," in Bennett's and Elliott's Physiology and Medicine of Diving, eds A. O. Brubakk and T. S. Neuman (Philadelphia: Saunders, Elsevier Science Ltd), 330-339.

Best, A. R., and Wilson, D. A. (2004). Coordinate synaptic mechanisms contributing to olfactory cortical adaptation. J. Neurosci. 24, 652-660.
Bolshakov,V.Y.,Golan,H., Kandel,E.R., and Siegelbaum, S. A. (1997). Recruitment of new sites of synaptic transmission during the cAMP-dependent late phase of LTP at CA3-CA1 synapses in the hippocampus. Neuron 19, 635-651.

Brauer, R. W., Beaver, R. W., Lahser, S., McCall, R. D., and Venters, R. (1979). Comparative physiology of the highpressure neurological syndrome: compression rate effects. J. Appl. Physiol. $46,128-135$.

Calabrese, B., Tabarean, I. V., Juranka, P., and Morris, C. E. (2002). Mechanosensitivity of N-type calcium channel currents. Biophys. J. 83, 2560-2574.

Chance, F. S., Nelson, S. B., and Abbott, L. F. (1998). Synaptic depression and the temporal response characteristics of V1 cells. J. Neurosci. 18, 4785-4799.

Cook, D. L., Schwindt, P. C., Grande, L. A., and Spain, W. J. (2003). Synaptic depression in the localization of sound. Nature 421, 66-70.

Daniels, S., and Grossman, Y. (2003). "Biological effects of pressure," in Bennett and Elliott's Physiology and Medicine of Diving, eds Brubakk, A. O., and Neuman, T. S. (Philadelphia: Saunders, Elsevier Science Ltd), 265-299.

Destexhe, A., Mainen, Z.F., and Sejnowski, T. J. (1994). Synthesis of models for excitable membranes, synaptic transmission and neuromodulation using a common kinetic formalism. J. Comp. Neurosci. 1, 195-230.

Dittman, J. S., and Regehr, W. G. (1998). Calcium dependence and recovery kinetics of presynaptic depression at the climbing fiber to Purkinje cell synapse. J. Neurosci. 18, 6147-6162.

Elmqvist, D., and Quastel, D. M. (1965). A quantitative study of end-plate

be redistributed (among the sequential $E_{\mathrm{x}}$ ) in a $\mathrm{Ca}^{2+}$-dependent manner. These frequency-dependent phenomena may explain both, a relatively conserved performance at HP and also pathological features of HPNS that may depend on environmental stimuli inducing high-frequency activity. Such a mechanism may also explain behavioral adaptability and regular performance of diving mammals (whales, seals, etc.) at great depths, and may even shed light on the problem of their susceptibility to underwater noise and sonar activity (Talpalar and Grossman, 2005).

\section{ACKNOWLEDGMENTS}

We thank Dr. P. Blinder at Physics Dept. of UCSD for critical reading and comments on the manuscript, and Dr. A. Loebel for discussions. This study was partially supported by USA Office of Naval Research (ONR) grant no. N00014-10-1-0163 to Yoram Grossman, and by the Univ. of Antwerp (NOI), the Belgian Interuniversity Attraction Pole (IAP P6/29) and the Francqui Foundation grants to Michele Giugliano.

potentials in isolated human muscle. J. Physiol. 178, 505-529.

Etzion, Y., and Grossman, Y. (1999) Spontaneous $\mathrm{Na}^{+}$and $\mathrm{Ca}^{2+}$ spike firing of cerebellar Purkinje neurons at high pressure. Pflugers Arch. 437, 276-284.

Etzion, Y., and Grossman, Y. (2000) Pressure-induced depression of synaptic transmission in the cerebellar parallel fibre synapse involves suppression of presynaptic $\mathrm{N}$-type $\mathrm{Ca} 2+$ channels. Eur. J. Neurosci. 12, 4007-4016.

Etzion, Y., Mor, A., and Grossman Y. (2009). Differential modulation of cerebellar climbing fiber and parallel fiber synaptic responses at high pressure. J. Appl. Physiol. 106, 729-736.

Fagni, L.,Zinebi, F., and Hugon, M. (1987) Evoked potential changes in rat hippocampal slices under helium pressure. Exp. Brain Res. 65, 513-519.

Fernandez-Alfonso, T., and Ryan, T. A. (2004). The kinetics of synaptic vesicle pool depletion at CNS synaptic terminals. Neuron 41, 943-953.

Fortune, E. S., and Rose, G. J. (2001). Short-term synaptic plasticity as a temporal filter. Trends Neurosci. 24, 381-385.

Foster, K. A., and Regehr, W. G. (2004) Variance-mean analysis in the presence of a rapid antagonist indicates vesicle depletion underlies depression at the climbing fiber synapse. Neuron 43, 119-131.

Fuhrmann, G., Segev, I., Markram, H., and Tsodyks, M. (2002). Coding of temporal information by activitydependent synapses. J. Neurophysiol. 87, 140-148.

Geinisman, Y. (1993). Perforated axospinous synapses with multiple, completely partitioned transmission zones: probable structural intermediates in synaptic plasticity. Hippocampus 3 , 417-433.

Geinisman, Y., Berry, R. W., Disterhoft, J. F., Power, J. M., and Van der Zee, E. A. (2001). Associative learning elicits the formation of multiple-synapse boutons. J. Neurosci. 21, 5568-5573.

Gilman, S. C., Kumaroo, K. K., and Hallenbeck, J. M. (1986). Effects of pressure on uptake and release of calcium by brain synaptosomes. J. Appl. Physiol. 60, 1446-1450.

Golan, H., and Grossman, Y. (1992). Synaptic transmission at high pressure: effects of $[\mathrm{Ca} 2+]$ o. Comp. Biochem. Physiol. Comp. Physiol. 103, 113-118.

Golan, H., Moore, H. J., and Grossman, Y. (1994). Quantal analysis of presynaptic inhibition, low $\left[\mathrm{Ca}^{2+}\right] 0$, and high pressure interactions at crustacean excitatory synapses. Synapse 18, 328-336.

Golan, H., Colton, J. S., Moore, H. J., and Grossman, Y. (1995). Analysis of evoked and spontaneous quantal release at high pressure in crustacean excitatory synapses. Pflugers Arch. 430, 617-625.

Golan, H., Moore, H. J., and Grossman, Y. (1996). Pressure exposure unmasks differences in release properties between high and low yield synapses of a single excitatory axon. Neuropharmacology 35, 187-193.

Grossman, Y., Colton, J. S., and Gilman, S. C. (1991). Interaction of Ca-channel blockers and high pressure at the crustacean neuromuscular junction. Neurosci. Lett. 125, 53-56.

Grossman, Y., and Kendig, J. J. (1990). Evidence for reduced presynaptic $\mathrm{Ca} 2+$ entry in a lobster neuromuscular junction at high pressure. J. Physiol. 420, 355-364.

Heinemann, S. H., Conti, F., Stühmer, W., and Neher, E. (1987). Effects of 
hydrostatic pressure on membrane processes. Sodium channels, calcium channels, and exocytosis. J. Gen. Physiol. 90, 765-778.

Kilbride, J., Rush, A. M., Rowan, M. J., and Anwyl, R. (2001). Presynaptic group II mGluR inhibition of short-term depression in the medial perforant path of the dentate gyrus in vitro. J. Neurophysiol. 85, 2509-2515.

Liley, A. W., and North, K. A. (1953). An electrical investigation of effects of repetitive stimulation on mammalian neuromuscular junction. $J$. Neurophysiol. 16, 509-527.

Loebel, A., Silberberg, G., Helbig, D., Markram, H., Tsodyks, M., and Richardson, M. J. E. (2009). Multiquantal release underlies the distribution of synaptic efficacies in the neocortex. Front. Comp. Neurosci. 3, 1-13.

Logue, P. E., Schmitt, F. A., Rogers, H. E., and Strong, G. B. (1986). Cognitive and emotional changes during a simulated 686- $\mathrm{m}$ deep dive. Undersea Biomed. Res. 13, 225-235.

Markram, H., and Tsodyks, M. (1996). Redistribution of synaptic efficacy between neocortical pyramidal neurons. Nature 382, 807-810.

Markram, H., Wang, Y., and Tsodyks, M. (1998). Differential signaling via the same axon of neocortical pyramidal neurons. Proc. Natl. Acad. Sci. U.S.A 95, 5323-5328.

Moser, E. I., and Andersen, P. (1994). Conserved spatial learning in cooled rats in spite of slowing of dentate field potentials. J. Neurosci. 14, 4458-4466.

Oheim, M., Kirchhoff, F., and Stuhmer, W. (2006). Calcium microdomains in regulated exocytosis. Cell Calcium 40, 423-439.
Otter T., and Salmon E. D. (1979). Hydrostatic pressure reversibly blocks membrane control of ciliary motility in Paramecium. Science 206, 358-361.

Otter, T., and Salmon, E. D. (1985). Pressure-induced changes in $\mathrm{Ca} 2+-$ channel excitability in Paramecium. J. Exp. Biol. 117, 29-43.

Press, W.H., Teukosky, S.A., Vetterling, W. T., and Flannery, B.P.(1992). Numerical Recipes in C,2nd edn. Cambridge, UK: Cambridge University Press.

Qian, J., and Noebels, J. L. (2001). Presynaptic Ca2+ channels and neurotransmitter release at the terminal of a mouse cortical neuron. J. Neurosci. 21, 3721-3728.

Rush, A. M., Wu, J., Rowan, M. J., and Anwyl, R. (2002). Group I metabotropic glutamate receptor (mGluR)dependent long-term depression mediated via p38 mitogen-activated protein kinase is inhibited by previous high-frequency stimulation and activation of mGluRs and protein kinase $\mathrm{C}$ in the rat dentate gyrus in vitro. $J$. Neurosci. 22, 6121-6128.

Schikorski, T., and Stevens, C. F. (1997). Quantitative ultrastructural analysis of hippocampal excitatory synapses. J. Neurosci. 17, 5858-5867.

Schikorski, T., and Stevens, C. F. (2001). Morphological correlates of functionally defined synaptic vesicle populations. Nat. Neurosci. 4, 391-395.

Schneggenburger, R., and Neher, E. (2000). Intracellular calcium dependence of transmitter release rates at a fast central synapse. Nature 406, 889-893.

Stevens, C. F. (2003a). Neurobiology: the importance of depression. Nature 421, 29-30.

Stevens, C. F. (2003b). Neurotransmitter release at central synapses. Neuron 40 , 381-388.
Stevens, C. F., and Wesseling, J. F. (1999). Identification of a novel process limiting the rate of synaptic vesicle cycling at hippocampal synapses. Neuron 24, 1017-1028.

Talpalar, A. E. (2002). Pressure effects on the performance of corticohippocampal synapses ( $\mathrm{PhD}$ thesis). Ben-Gurion University (English), Beer Sheva, Israel.

Talpalar, A. E. (2007). High pressure neurological syndrome (bilingual Spanish/English). Rev. Neurol. 45, 631-636.

Talpalar, A. E., and Grossman, Y. (2003). Modulation of rat corticohippocampal synaptic activity by high pressure and extracellular calcium: single and frequency responses. J. Neurophysiol. 90, 2106-2114.

Talpalar, A. E., and Grossman, Y. (2004). Enhanced excitability compensates for high-pressure-induced depression of cortical inputs to the hippocampus. J. Neurophysiol. 92, 3309-3319.

Talpalar, A. E., and Grossman, Y. (2005). Sonar versus Whales: noise may disrupt neural activity in deep-diving cetaceans. Undersea Hyperb. Med. 32, 135-139.

Talpalar, A. E., and Grossman, Y. (2006). CNS manifestations of HPNS: revisited. Undersea Hyperb. Med. 33, 205-210.

Toni, N., Buchs, P. A., Nikonenko, I., Bron, C. R., and Muller, D. (1999). LTP promotes formation of multiple spine synapses between a single axon terminal and a dendrite. Nature 402, 421-425.

Tsodyks, V. M., and Markram, H. (1997) The neural code between neocortical pyramidal neurons depends on neurotransmitter release probability. Proc. Natl. Acad. Sci. U.S.A. 94, 719-723.
Vaernes, R., Hammerborg, D., Ellertsen, B., Peterson, R., and Tonjum, S. (1985) CNS reactions at 51 ATA on trimix and heliox and during decompression. Undersea Biomed. Res. 12, 25-39.

Vaernes, R. J., Bergan, T., and Warncke, M. (1988). HPNS effects among 18 divers during compression to $360 \mathrm{msw}$ on heliox. Undersea Biomed. Res. 15, 241-255.

Vaernes, R. J., Klove, H., and Ellertsen, B. (1989). Neuropsychologic effects of saturation diving. Undersea Biomed. Res. 16, 233-251.

Wang, L. Y., and Kaczmarek, L. K. (1998). High-frequency firing helps replenish the readily releasable pool of synaptic vesicles. Nature 394, 384-388.

Zucker, R. S., and Regehr, W. G. (2002). Short-term synaptic plasticity. Ann. Rev. Physiol. 64, 355-405.

Conflict of Interest Statement: The authors declare that the research was conducted in the absence of any commercial or financial relationships that could be construed as a potential conflict of interest.

Received: 08 June 2010; paper pending published: 17 August 2010; accepted: 23 August 2010; published online: 15 October 2010.

Citation: Talpalar AE, Giugliano $M$ and Grossman Y (2010) Enduring medial perforant path short-term synaptic depression at high pressure. Front. Cell. Neurosci. 4:128. doi:10.3389/fncel.2010.00128 Copyright (C) 2010 Talpalar, Giugliano and Grossman. This is an open-access article subject to an exclusive license agreement between the authors and the Frontiers Research Foundation, which permits unrestricted use, distribution, and reproduction in any medium, provided the original authors and source are credited. 